\title{
AVALIAÇÃO DA INFLUÊNCIA DO USO E COBERTURA DO SOLO E DA RETIRADA DE ÁGUA SUBTERRÂNEA SOBRE A VAZÃO DO RIBEIRÃO TORTINHO - DF
}

\author{
ASSESSMENT OF THE INFLUENCE OF LAND USE/COVER AND THE GROUNDWATER \\ WITHDRAWAL ON RIBEIRÃO TORTINHO'S FLOW - DF
}

\author{
Alice Rocha Pereira ${ }^{a}$, Andréia de Almeida ${ }^{a}$, Sergio Koide ${ }^{a}$ \\ aUniversidade de Brasília (UnB) \\ alicerp@hotmail.com, dealmeida15@gmail.com, skoide@unb.br
}

Submissão: 29 de junho de 2021 Aceitação: 6 de novembro de 2021

\section{Resumo:}

A ocupação intensa e desordenada ocorrida nas últimas décadas na região do Núcleo Rural Lago Oeste (LO), inserida na bacia do ribeirão Tortinho, bem como, o aumento das atividades agrícolas e irrigação, passando a totalizar aproximadamente $22 \%$ da bacia, tornou-se um fator preocupante dado que o ribeirão Tortinho contribui para o abastecimento de água para consumo humano em Brasília. Ademais, em face à irregularidade da ocupação urbana, não há abastecimento de água pela companhia local e ocorre a explotação de águas subterrâneas no LO para abastecimento e irrigação. Logo, este trabalho teve como objetivo avaliar o efeito das alterações de uso e cobertura do solo na vazão do ribeirão Tortinho e analisar o impacto devido à exploração de águas subterrâneas sobre o escoamento de base no ribeirão Tortinho. Para avaliar a influência das mudanças ocorridas no uso e cobertura do solo sobre a vazão foi realizada simulação com o modelo de bacia SWAT e aplicado o teste de Kolmogorov-Smirnov nas séries de vazão, enquanto, na avaliação do efeito da retirada de água por poços na região sobre o escoamento de base, foram considerados cenários para a simulação com o modelo acoplado SWAT-MODFLOW. Observou-se que as alterações ocorridas na vazão simulada em face às mudanças de uso e cobertura (1975 e 2013) não foram estatisticamente significantes. Os cenários simulados com maior número de poços, baseados em levantamento de campo, como forma de aproximar mais à situação real, leva a uma extensa área de secamento na região do LO prolongando-se para dentro do Parque Nacional de Brasília, o que afetaria a vegetação nativa e o escoamento de base. Dessa forma, a retirada de águas subterrâneas no LO pode ter impacto significativo no nível freático no domínio poroso e, portanto, verifica-se a importância de hidrometração dos poços na região para que seja realizada a gestão adequada das águas da bacia.

Palavras-chave: modelagem hidrológica; vazão; SWAT; MODFLOW.

\section{Abstract:}

In the last decades, intense and disordered occupation occurred in Núcleo Rural Lago Oeste (LO) region, located in the Tortinho stream basin, as well as the increase in agricultural and irrigation activities comprising approximately $22 \%$ of the basin, therefore it became a worrisome factor given that Tortinho stream contributes to the water supply system of Brasília. Furthermore, groundwater exploitation occurs for supply and irrigation due to the absence of public water supply in LO by the local sanitation company. Therefore, this research work aimed to evaluate the effect of changes in land use and cover on Tortinho's flow and analyze the impact caused by the exploration of groundwater on the baseflow. The basin model SWAT was used to simulate flow and the Kolmogorov-Smirnov test was applied to the flow series in order to assess the influence of changes in land use and land cover on the flow. Additionally, to assess the effect of the water exploitation by wells on the baseflow, scenarios were considered for the simulation with the coupled model SWAT-MODFLOW. It was observed that changes in simulated flow due to changes in land use and cover (1975 and 2013) were not statistically significant. Scenarios with a larger number of wells, based on field survey, were simulated in order to provide a more realistic representation. These scenarios led to an extensive drying area in LO region 
extending into the Brasília National Park, which can affect pristine vegetation and the baseflow. Therefore, the groundwater exploration in LO can significantly change the water table in the porous domain, thus, stressing the importance of well water meteringin the region for improving basin water management.

Keywords: hydrological modeling; flow; SWAT; MODFLOW.

\section{INTRODUÇÃO}

O ciclo hidrológico em uma bacia hidrográfica pode sofrer alterações conforme as mudanças na cobertura no solo. A expansão da urbanização e de atividades agrícolas, especialmente na ausência de ordenamento territorial, tende a reduzir a permeabilidade do solo e o tempo de concentração da água na bacia (SILVA E GOMES, 2021; MARIANO, 2021) Estas mudanças intensificam o escoamento superficial e a vazão de pico, acarretando sobrecarga dos corpos hídricos receptores (HU et al., 2020; ZHANG et al., 2020). Em contraponto reduzem-se a infiltração e, consequentemente, a recarga de aquíferos, comprometendo o escoamento de base nos períodos de seca que é essencial para a manutenção dos serviços ecossistêmicos associados aos ambientes aquáticos (DE GRAAF et al., 2019; SEKERCIOGLU, 2010; ZHANG et al., 2020). Com isso, é essencial compreender o comportamento hidrológico das bacias em função de mudanças na cobertura do solo.

Nesse sentido, modelos hidrológicos são uma alternativa amplamente utilizada para a simulação das componentes do balanço hídrico e suas alterações frente às mudanças nos fatores ambientais. Hu et al. (2020), por exemplo, quantificaram os impactos decorrentes das atividades antrópicas e das mudanças climáticas no escoamento superficial da bacia do rio Min-Tuo na China, com os modelos SWAT (Soil and Water Assessment Tool) e Budyko. Os autores observaram que, além da precipitação, parâmetros relacionados à paisagem também influenciam o escoamento superficial. Zhang et al. (2020), utilizando modelo SWAT modificado (SWAT-T), observaram um aumento significativo no escoamento superficial devido ao desmatamento e a urbanização com reflexos para a saúde da população e dos ecossistemas na bacia do rio North Johnstone, na Austrália.

Os modelos hidrológicos permitem compreender o ciclo hidrológico, podendo assim subsidiar o manejo do uso do solo e a gestão dos recursos hídricos, além de auxiliar na tomada de decisão e proposição de políticas ambientais, (FERREIRA et al., 2021; FREDERIKSEN E
MOLINA-NAVARRO, 2021; JEYRANI et al., 2021; KONDO et al., 2021; LIU et al., 2019). O SWAT, por exemplo, é um modelo de bacia, de simulação contínua, tendo como vantagens sua eficiência computacional, seu código aberto, ser modular e flexível quanto a simulação de questões relacionadas aos recursos hídricos (NEITSCH et al., 2011; ARNOLD et al., 1998; GASSMAN et al., 2007; SARASWAT et al., 2015). O SWAT tem sido aplicado com frequência para analisar e prever o impacto do manejo do solo, a exemplo da expansão de áreas agrícolas ou urbanas, sobre os recursos hídricos (RODRIGUES et al., 2015; BLAINSKI et al., 2017; SINGH et al., 2018; ZHANG et al., 2020).

Já o MODFLOW (Modular Three-Dimensional Finite-Difference Groundwater Flow) consiste em um modelo hidrológico de águas subterrâneas, modular, distribuído, aplicado para a simulação do fluxo e da interação entre o rio e o aquífero de maneira contínua, incluindo questões como extração de águas subterrâneas, nível freático e escoamento de base (HARBAUGH, 2005), como nos estudos de Cho et al. (2009) e Guira (2018) que simularam os efeitos do uso do solo sobre o fluxo das águas subterrâneas.

A integração entre os modelos SWAT e MODFLOW combina os processos superficiais e subterrâneos e pode, desse modo, aprimorar a representação dos processos físicos da bacia (PERKINS e SOPHOCLEOUS, 1999) e as simulações de recarga, fluxo de água subterrânea e variações do nível freático (SOPHOCLEOUS e PERKINS, 2000). Em suma, o modelo acoplado SWAT-MODFLOW permite a avaliação de estratégias de gestão de água e de impactos naturais e antropogênicos sobre as águas superficiais e subterrâneas (SOPHOCLEOUS et al.,1999; GUZMAN et al., 2015; KE, 2014; PRIYA E MANJULA, 2021).

Liu et al. (2019) comparam a utilização do SWAT e do SWAT-MODFLOW para a quantificação da vazão em resposta a exploração de águas subterrâneas para irrigação ou abastecimento de água em escala de bacia. Os autores verificaram uma melhor performance do modelo acoplado SWAT-MODFLOW, com 
representações mais realistas quanto à avaliação dos impactos relacionados a extração de águas subterrâneas. Szymkiewicz et al. (2020), acoplaram os modelos SWAT, MODFLOW-NWT e o MT3DMS com o intuito de avaliar a influência das práticas agrícolas e do uso do solo nas águas subterrâneas, além das descargas de água subterrânea para o mar, na Polônia. Observaramse nesse estudo padrões sazonais distintos para a recarga e descarga de água subterrânea para o mar. O efeito da variação do tipo de cultura sobre a recarga e a descarga das águas subterrâneas é mais significativo do a influência causada pela mudança de uso do solo.

Neste trabalho, a bacia do ribeirão Tortinho, selecionada como área de estudo, localiza-se em uma região de relevância para a conservação ambiental no Distrito Federal, Brasil. A partir dos anos 90, uma porção dessa bacia começou a ser ocupada e urbanizada de forma intensa, desordenada e em condomínios horizontais à borda do Parque Nacional de Brasília (a sudoeste) e à borda das drenagens da bacia do Rio Maranhão (a nordeste) (FORTES et al., 2003), dando origem à região denominada Lago Oeste (LO). Adicionalmente, dentre as áreas ocupadas, houve um crescimento significativo do uso agrícola (GREENTEC, 2010). Como o LO não é abastecido pela Companhia de Saneamento Ambiental do Distrito Federal (CAESB), a população realizou a perfuração de poços, rasos e profundos, para a captação de água subterrânea, principalmente, para abastecimento e irrigação.

Diante desse contexto, considerando que a bacia do ribeirão Tortinho contribui para 0 abastecimento de parte de Brasília, a ocorrência, magnitude, evolução e as consequências dos impactos ambientais face a urbanização e exploração de águas subterrâneas, este trabalho teve como objetivos 1) avaliar o efeito das alterações da cobertura do solo, iniciadas nos anos 90 no LO, na vazão do ribeirão Tortinho usando o modelo SWAT, calibrado e verificado; e 2) analisar o impacto da retirada de água por poços sobre o fluxo de base no ribeirão Tortinho utilizando o modelo SWAT-MODFLOW. O presente trabalho contribuiu, portanto, para a avaliação preliminar do comportamento das vazões na bacia e da contribuição das águas subterrâneas ao ribeirão Tortinho, inserido no Parque Nacional. Além disso, com base em revisão da literatura, este é o primeiro estudo na bacia do ribeirão Tortinho considerando e simulando os aspectos relativos à urbanização da bacia, retirada de águas subterrâneas, seus impactos e alterações de vazão.

\section{METODOLOGIA}

A metodologia do presente trabalho é apresentada de forma sintetizada na Figura 1.

\section{1. Área de Estudo}

A área de estudo compreende a bacia do ribeirão Tortinho (Figura 2), localizada em Brasília, Distrito Federal, com área aproximada de $41 \mathrm{~km}^{2}$. A bacia encontra-se entre os meridianos $48^{\circ} 0^{\prime} 0^{\prime \prime} \mathrm{W}$ e $47^{\circ} 54^{\prime} 0^{\prime \prime} \mathrm{W}$ e os paralelos $15^{\circ} 34^{\prime} 30^{\prime \prime} \mathrm{S}$ e $15^{\circ} 39^{\prime} 30^{\prime \prime}$.

A região apresenta clima tropical de altitude e um dos maiores índices pluviométricos do Distrito Federal, com médias anuais entre 1600 e 1650mm (Netto, 2005). As altitudes variam de 1060 a $1300 \mathrm{~m}$, predominando declividades abaixo de $10 \%$. Quanto à pedologia, observa-se 0 predomínio de Latossolo Vermelho, além da presença de Latossolo Vermelho-Amarelo, solos Hidromórficos, Cambissolos e Laterita Hidromórfica (REATTO et al., 2004).

Apesar de incluir o Parque Nacional de Brasília (PNB) em uma porção significativa, aproximadamente $78 \%$, a bacia em estudo abrange grande parte do Núcleo Rural Lago Oeste (LO), localizado no divisor de águas superficiais na região $\mathrm{N}-\mathrm{E}$ da bacia. A ocupação antrópica no $L O$, iniciada na década de 70, tomou proporções significativas a partir dos anos 90, com um aumento expressivo do parcelamento territorial e da agricultura, além da especulação e da pressão imobiliária, alterando significativamente a paisagem local e aumentando a pressão sobre os recursos naturais (GREENTEC, 2010). Em 2004, o LO possuía aproximadamente 8760 habitantes (GREENTEC, 2014), já em 2018, segundo a Agência Câmara Notícias (2018), LO possui aproximadamente 1250 chácaras e em torno de 10mil habitantes.

A área da bacia do ribeirão Tortinho que inclui o LO apresenta relevância ambiental por: i) ser adjacente ao PNB e à Reserva Biológica da Contagem; ii) estar inserido na Área de Proteção Ambiental (APA) do Planalto Central; iii) ocupar parte da zona de amortecimento e transição do PNB; e iv) estar sobre a Área de Proteção de Manancial Torto/Santa Maria (GREENTEC, 2010; SEMARH, 2014; NETTO, 2005; PDOT, 2009).

Outro fator preocupante com relação às mudanças na cobertura do solo no LO é a 
captação de água subterrânea, para abastecimento e irrigação, em face à ausência de abastecimento pela companhia de saneamento local (CAESB) (GREENTEC, 2014). Os autores do presente trabalho também observaram que no cadastro da Agência Reguladora de Águas,
Energia e Saneamento do Distrito Federal (ADASA) (2017) estavam registrados apenas 593 poços, o que representa aproximadamente $47 \%$ do número de lotes e sem abastecimento público na região, considerando o levantamento da Agência Câmara Notícias (2018).

Figura 1. Síntese metodológica do presente trabalho.

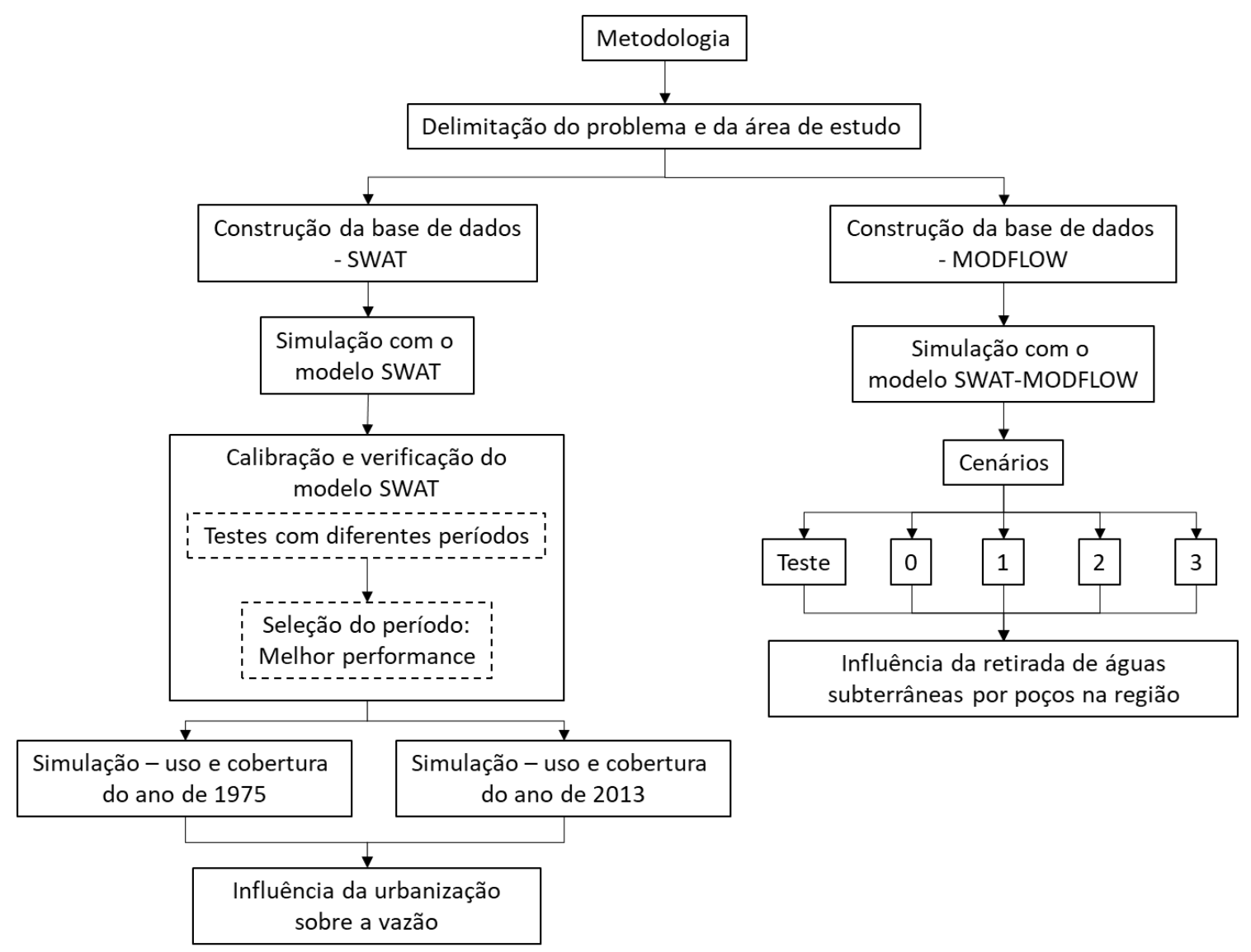

Fonte: Os autores.

\subsection{Modelo SWAT}

O Soil and Water Assessment Tool (SWAT) é um modelo conceitual desenvolvido pelo Serviço de Pesquisa Agrícola dos EUA (ARS) que opera em escala de bacia, continuamente no tempo e em passo diário para a previsão de impactos resultantes da gestão e manejo do solo nos recursos hídricos até mesmo em bacias não monitoradas. O SWAT é um modelo chuva-vazão, de base física que utiliza a equação do balanço hídrico para a realização dos cálculos de fluxo e transporte (NEITSCH et al., 2011; ARNOLD et al., 1998).

O SWAT realiza a simulação em duas fases: a fase do terreno e a fase do roteamento ou itinerário hidrológico. A primeira diz respeito a quantidade de água, sedimentos, nutrientes e pesticidas, para cada sub-bacia, presentes no canal principal, já a segunda se refere ao movimento da água, sedimentos, nutrientes e pesticidas pelos canais da bacia até a descarga (NEITSCH et al., 2011).

\subsection{Dados de entrada e configuração do modelo SWAT}

O SWAT requer dados climáticos, topográficos, pedológicos, de uso e cobertura do solo e de operações de gestão e manejo do solo (versão 2012.10.19), conforme detalhado na Tabela 1. A classificação não-supervisionada Iso Cluster aplicada à imagem Landsat1-5MSS de julho de 1975 forneceu o mapa de uso e cobertura do solo para o ano de 1975 (Figura 3a). Este mapa representou o período de urbanização incipiente devido à ausência de imagens e a extensiva 
cobertura de nuvens em imagens obtidas até 1984 (Tabela 1). A imagem utilizada apresentou interferências pontuais de nuvens e áreas de queimadas, que foram consideradas como área naturais. Além disso, as culturas perenes e anuais foram agrupadas na classe agricultura por não ser possível distingui-las na imagem de 1975. O mapa de uso e cobertura do solo de 2013 (Figura 3b) foi obtido por meio da classificação manual, em escala 1: 1000, da ortofotocarta de abril de 2013, fornecida pela Terracap (Tabela 1).

Figura 2. Localização da área de estudo (bacia do ribeirão Tortinho).

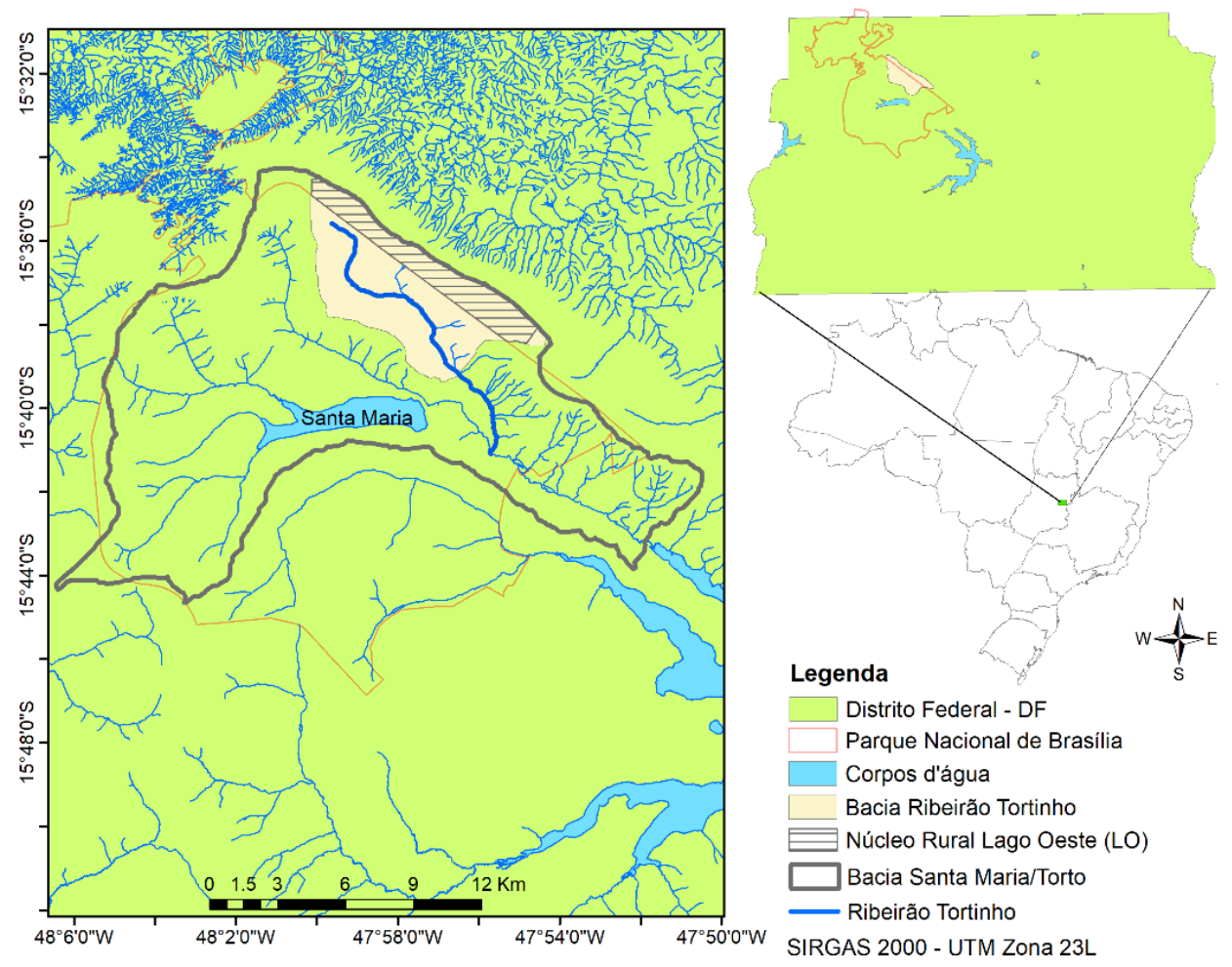

Fonte: Os autores.

Tabela 1. Dados de entrada do modelo SWAT.

\begin{tabular}{|c|c|c|}
\hline Dados de entrada & Fonte & Resolução \\
\hline $\begin{array}{l}\text { Dados climáticos: } \\
\text { 1) Precipitação, } \\
\text { 2) Temperaturas } \\
\text { máximas e mínimas } \\
\text { do ar, radiação solar, } \\
\text { velocidade do vendo } \\
\text { e umidade relativa) }\end{array}$ & $\begin{array}{c}\text { 1) Estações Contagem (código 1547010), } \\
\text { Fazenda Santa Elisa (código 1548013) e Santa } \\
\text { Maria (código 1547017), operadas pela CAESB. } \\
\text { Ponderados considerando as áreas de } \\
\text { influência obtidas pelo método de Thiessen; } \\
\text { 2) Estação Brasília (código 83377), operada } \\
\text { pelo Instituto Nacional de Meteorologia } \\
\text { (INMET). }\end{array}$ & $\begin{array}{c}\text { Diária } \\
\text { (Período: } 1971 \text { a 2017) }\end{array}$ \\
\hline Topografia & $\begin{array}{c}\text { Sistema Cartográfico do Distrito Federal - } \\
\text { SICAD (SEDHAB, 2009) * }\end{array}$ & $\begin{array}{l}\text { Curva de nível com } \\
\text { espaçamento de } 5 \mathrm{~m}\end{array}$ \\
\hline Pedologia & $\begin{array}{l}\text { Empresa Brasileira de Pesquisa Agropecuária } \\
\text { (EMBRAPA), atualizado por Reatto (2004) }\end{array}$ & $1: 100000$ \\
\hline $\begin{array}{l}\text { Uso e Cobertura do } \\
\text { Solo }\end{array}$ & $\begin{array}{l}\text { 1) Classificação não-supervisionada Isso } \\
\text { Cluster da imagem Landsat1-5MSS de julho de } \\
\qquad 1975 \text {; } \\
\text { 2) Classificação manual da ortofotocarta de abril } \\
\text { de } 2013 \text { fornecida pela Terracap. }\end{array}$ & $\begin{array}{l}\text { 1) resolução espacial de } \\
80 \mathrm{~m} ; \\
\text { 2) resolução espacial de } \\
24 \mathrm{~cm}\end{array}$ \\
\hline
\end{tabular}

* Comparado com dados obtidos por levantamento em campo com GPS Trimble.

Fonte: Os autores. 
As classes de solo foram agrupadas por similaridade, considerando o banco de dados adaptado para as características dos solos brasileiros fornecido por Ferrigo (2014), apresentados na Figura 4. Portanto, de posse dos mapas de uso e cobertura do solo (1975 e 2013), do mapa pedológico adaptado e dos dados climáticos, a bacia de estudo foi delineada com base no MDE. Em seguida, foram geradas as HRUs para os cenários de 1975 e 2013.

Figura 3. Uso e ocupação do solo para a bacia do ribeirão Tortinho para (a) 1975 e (b) 2013.

(a)

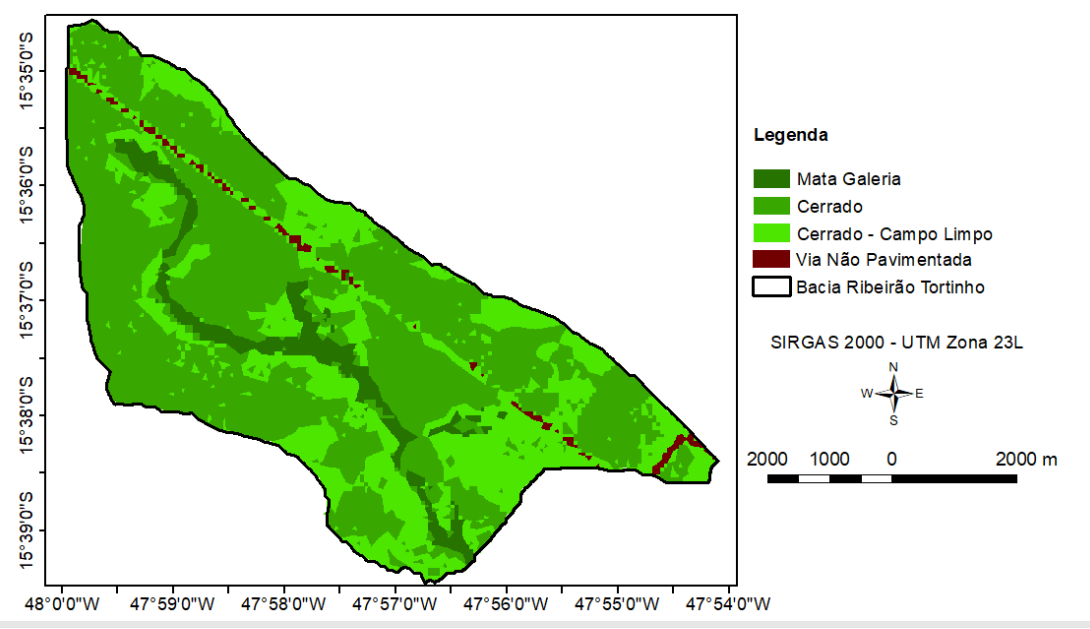

(b)

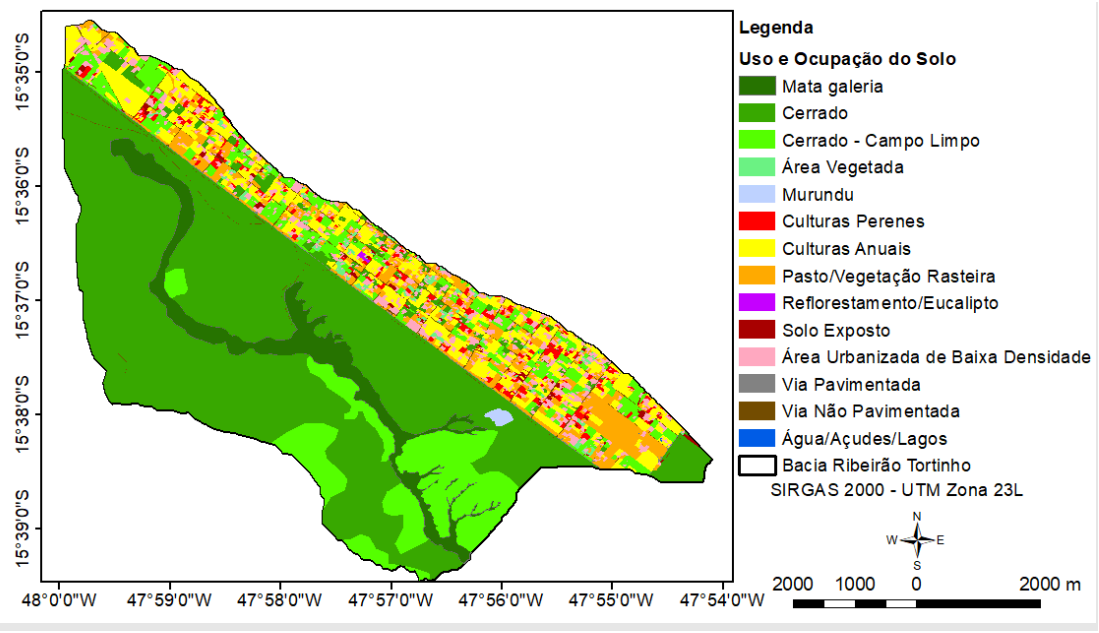

Fonte: Os autores.

Figura 4. Classificação dos solos da bacia do ribeirão Tortinho.

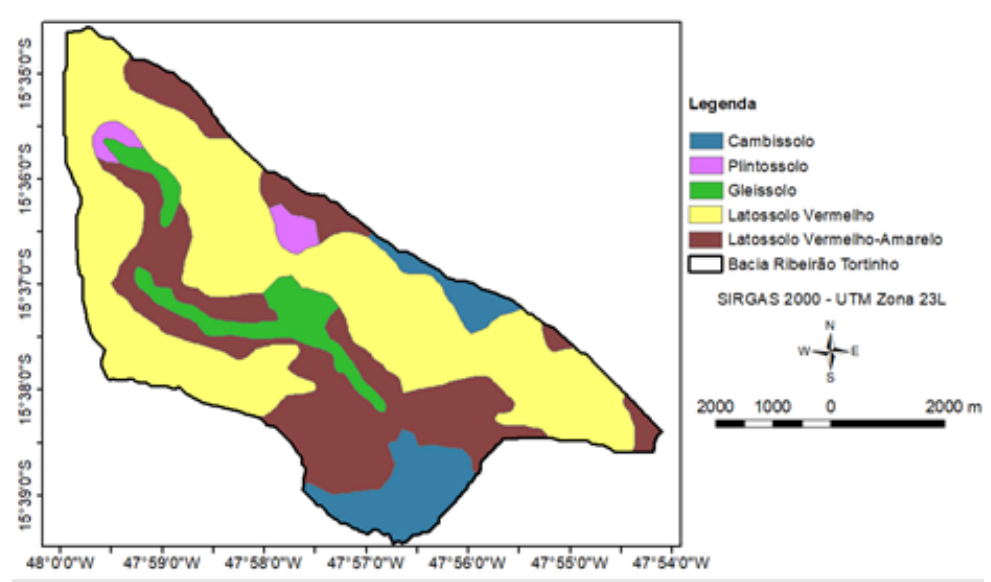

Fonte: Os autores. 
Ademais, replicaram-se os dados observados de 1971 a 1973 para a obtenção de uma série sintética representativa do período de 1968 a 1970, possibilitando o aquecimento do modelo sem a redução dos dados disponíveis para a calibração (1971-1975), conforme as recomendações de Daggupati et al. (2015).

A série de dados fluviométricos da Estação Torto-Granja (60477300) (Figura 5), operada pela CAESB, foi utilizada para a calibração e verificação do modelo. Contudo, essa estação contabiliza não apenas o escoamento da bacia do ribeirão Tortinho, mas também a contribuição das bacias do reservatório de Santa Maria, apesar de praticamente não ocorrer vertimento na barragem, e do córrego Três Barras. Por esse motivo, os dados hidrológicos selecionados foram transferidos para o exutório da bacia do ribeirão Tortinho calculando-se a vazão específica da área de contribuição da estação Torto-Granja, com exceção da área do reservatório Santa Maria, e multiplicando pela área da bacia do ribeirão Tortinho. Segundo Lima et al. (2008), a estimativa de vazão por "vazão específica" é adotada em bacias não monitoradas ou com baixa densidade de postos fluviométricos, como é o caso desse estudo, já que a vazão dependente fortemente da área de drenagem, sendo assim, possível estimar a ordem de grandeza da vazão ao longo do corpo d'água.

Além disso, é importante ressaltar que a Estação Torto-Granja localiza-se à montante da barragem do Torto, também utilizada para abastecimento público de água no DF. Com isso, desde 1971, 31 curvas-chave foram elaboradas para a Estação Torto-Granja devido à influência do remanso, que ocorre quando a barragem verte e não há captação, afetando as medições, principalmente, nos períodos de vazões baixas. Portanto, há incertezas associadas à curvas-chave e às vazões calculadas com base nesta curva. $O$ efeito do remanso, intensificado pelo assoreamento na barragem, pode induzir à elevação da cota do ribeirão do Torto e, consequentemente, resultar em dados de vazão superestimados. Contudo, análises de consistência dos dados não compreendem o escopo deste trabalho. Incertezas nos dados vazão obtidos por meio da curva-chave foram abordadas apenas na discussão dos resultados, especialmente na ocorrência de valores anômalos pontuais de vazão e carga superestimadas durante a estação seca.

Alterações de seção e mesmo modificações na calha são complexas devido à localização no Parque Nacional de Brasília, que requer autorização do IBAMA/ICMBio para intervenções na unidade de conservação. Apesar das limitações, a estação Torto-Granja é a única fonte de dados hidrológicos para a bacia em estudo, uma vez que, na Estação Torto-Lago, localizada mais a jusante, não há dados disponíveis de captação de água para consumo, impossibilitando o uso da série para os processos de calibração e verificação.

\subsection{Calibração e Verificação do Modelo SWAT}

A calibração, verificação e análise de sensibilidade de modelos do SWAT podem ser efetuadas com o software de domínio público SWAT Calibration and Uncertainty Programs (SWAT-CUP). Para tanto, o SWAT-CUP permite a utilização dos seguintes algoritmos de otimização: Sequential Uncertainty Fitting (SUFi-2), Particle Swarm Optimization (PSO), Generalized Likelihood Uncertainty Estimation (GLUE), Parameter Solution (ParaSol) e Markov Chain Monte Charlo (MCMC). Estes diferem quanto a estratégia usada para alcançar a melhor faixa de valores para os parâmetros que satisfaça ao limiar da função objetivo escolhida.

Neste trabalho, a calibração e a verificação do modelo foram realizadas com série mensal de forma automática com o software SWAT-CUP 2012 versão 5.1.6.2, algoritmo SUFi-2. A partir da análise de imagens de satélite disponibilizadas pela USGS (United States Geological Survey), definiu-se o período de 1971 a 1986 como um período de pré-urbanização a ser utilizado na calibração e verificação, evitando a influência da urbanização sobre os dados, sendo possível analisar o comportamento da bacia sem influência da urbanização e com influência da urbanização ao passo que está se considerando dois mapas distintos de uso e cobertura do solo (de 1975 e de 2013).

Dessa maneira, a calibração e a verificação foram realizadas avaliando-se dados de diferentes períodos entre os anos de 1971 e 1986, períodos estes selecionados conforme recomendações de Daggupati et al. (2015). A utilização de dados após o início da urbanização foi condicionada a avaliação prévia da influência da alteração da cobertura do solo na vazão do ribeirão Tortinho. Logo, não havendo influência significativa, foram adicionadas às etapas de calibração e verificação dados, entre 1987 e 1990. A Figura 6 apresenta 
um esquema simplificado da metodologia utilizada.

Os parâmetros utilizados na calibração e verificação do modelo SWAT, método de calibração e faixa de variação (Tabela 2) foram definidos conforme Ferrigo (2014), Távora (2017) e Arnold et al. (2012).

Figura 5. Estações fluviométricas na região de estudo.

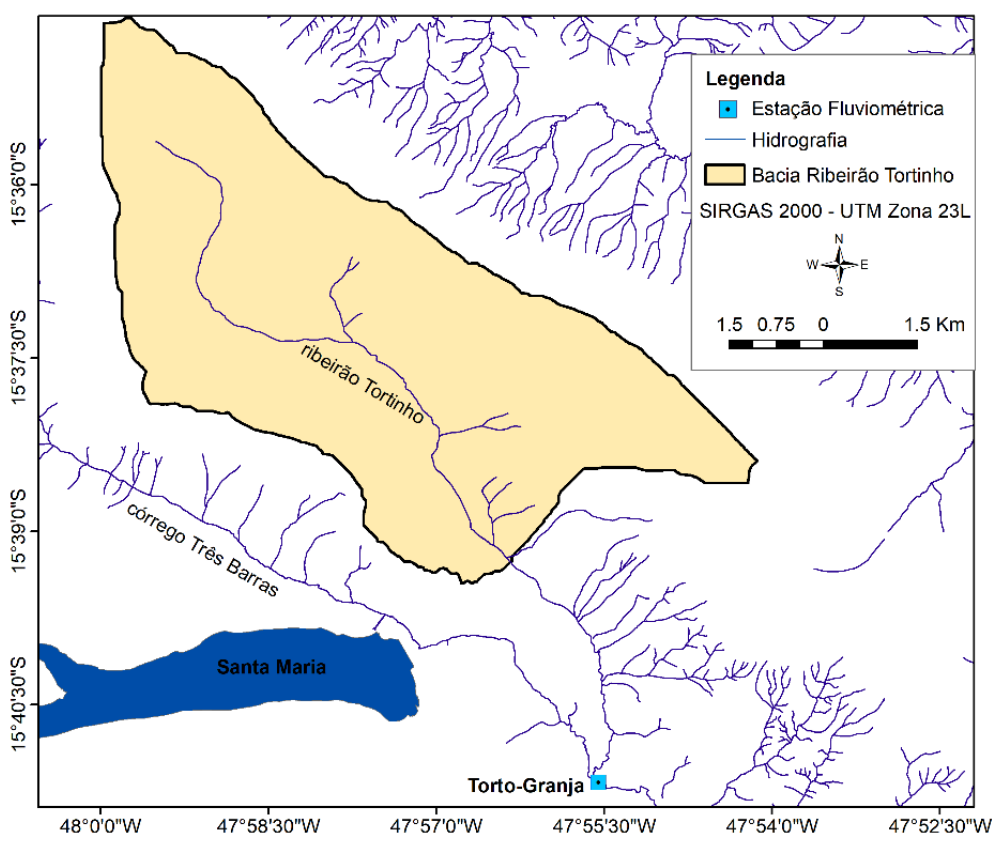

Fonte: Os autores.

Figura 6. Esquema metodológico simplificado para calibração e verificação.

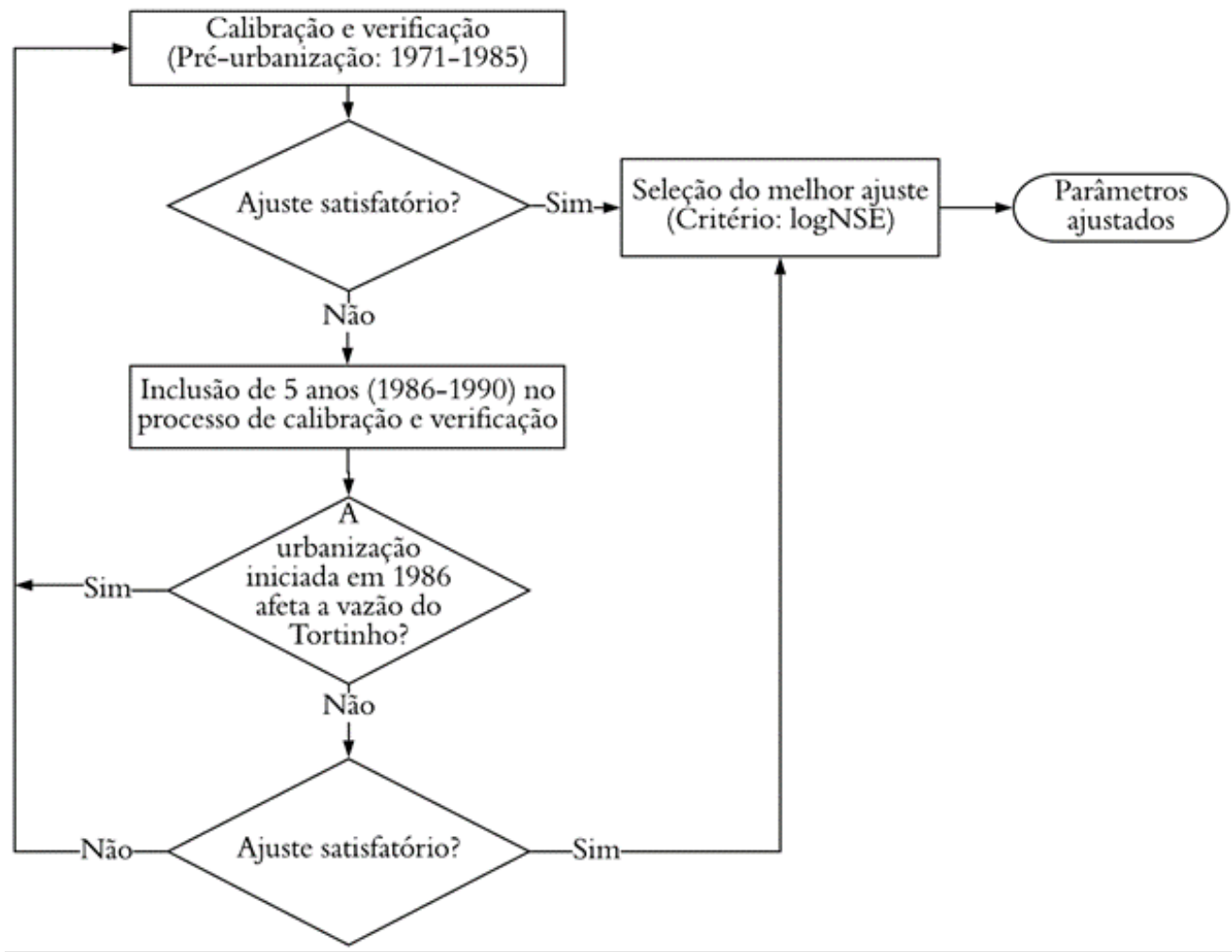

Fonte: Os autores. 
Previamente à calibração, efetuou-se a análise de sensibilidade dos parâmetros (Tabela 2) pelos métodos one-at-a-time (local) e all-at-a-time (global) (ABBASPOUR, 2015; KOUCHI et al., 2017), utilizando o SWAT-CUP. Apesar da análise de sensibilidade mostrar que o modelo não é sensível aos parâmetros SOL_K, ESCO,
GW_DELAY, CN2, RCHRG_DP, SHALLST, SOL BD, OV N, ANION EXCL e GW REVAP, pode-se observar redução na qualidade dos resultados da calibração sem considerá-los. Portanto, optou-se pela calibração utilizando-se todos os parâmetros.

Tabela 2. Parâmetros, método e faixa de variação usados na calibração.

\begin{tabular}{|c|c|c|c|}
\hline Parâmetro & Definição & Método* & $\begin{array}{l}\text { Faixa de } \\
\text { variação }\end{array}$ \\
\hline SOL_K(..).sol & Condutividade hidráulica saturada & M & $-1.95-0.8$ \\
\hline SOL_AWC.sol & Capacidade de água disponível na camada de solo & M & $-0.2-0.5$ \\
\hline SOL_BD(..).sol & Densidade aparente do solo & $\mathrm{M}$ & $-0.93-0.6$ \\
\hline DEEPST.gw & Profundidade inicial da água no aquífero profundo & S & $0-3000$ \\
\hline GW_REVAP.gw & $\begin{array}{l}\text { Coeficiente "revap" das águas subterrâneas (ascensão } \\
\text { da água à zona insaturada) }\end{array}$ & S & 0.02.- 0.1 \\
\hline GWHT.gw & Altura inicial das águas subterrâneas & S & $0-25$ \\
\hline RCHRG_DP.gw & Fração percolada para o aquífero profundo & S & $0-1$ \\
\hline GW_DELAY.gw & Tempo de atraso das águas subterrâneas & A & $-20-450$ \\
\hline GWQMN.gw & $\begin{array}{l}\text { Limiar de profundidade para a água no aquífero raso } \\
\text { necessário para que ocorra o fluxo de retorno }\end{array}$ & S & $0-1228$ \\
\hline REVAPMN.gw & $\begin{array}{c}\text { Limiar de profundidade para a água no aquífero raso } \\
\text { necessário para que ocorra o "revap" ou percolação } \\
\text { para o aquífero profundo }\end{array}$ & S & $0-500$ \\
\hline SHALLST.gw & Profundidade inicial da água no aquífero raso & S & $\begin{array}{c}1000- \\
5000\end{array}$ \\
\hline ESCO.hru & Fator de compensação de evaporação do solo & S & $0.4-1$ \\
\hline EPCO.bsn & Fator de compensação de absorção pelas plantas & S & $0-1$ \\
\hline ANION_EXCL.sol & $\begin{array}{l}\text { Fração de porosidade pelos quais os ânions são } \\
\text { excluídos }\end{array}$ & M & $0.1-1$ \\
\hline CN2.mgt & Curva número na condição II inicial & $\mathrm{M}$ & $-0.3-0.2$ \\
\hline SURLAG.bsn & Coeficiente de atraso do escoamento superficial & $\mathrm{S}$ & $0-10$ \\
\hline OV_N.hru & $\begin{array}{l}\text { Coeficiente de Manning " } n \text { " para o escoamento } \\
\text { superficial }\end{array}$ & M & $0-0.8$ \\
\hline
\end{tabular}

${ }^{*} \mathrm{M}=$ multiplicativo, $\mathrm{S}=$ substitutivo $\mathrm{A}=$ aditivo

Fonte: Os autores.

\subsubsection{Avaliação da influência do uso e cobertura na vazão do ribeirão Tortinho}

Com o intuito de verificar se ocorreu impacto significativo nas vazões do ribeirão Tortinho devido às alterações de uso e cobertura do solo na região do LO, foram aplicados teste de normalidade de Kolmogorov-Smirnov e teste de hipótese para avaliar a semelhança estatística entre as séries de vazão do ribeirão Tortinho dos anos de 1975 (préurbanização ) e 2013 (urbanização). O teste de normalidade de Kolmogorov-Smirnov foi aplicado para as séries de vazão simuladas dos períodos seco e chuvoso nos anos de 1975 e 2013. Os meses de maio a setembro foram considerados como período seco e os meses de outubro a abril foram considerados período chuvoso, conforme os dados de pluviometria provenientes da Estação Brasília, operada pelo INMET. Admitindo normalidade na distribuição dos dados das séries, aplicou-se o Teste t-pareado para as médias das vazões acumuladas nos períodos secos e chuvosos de 1975 e 2013. Valores p resultante do teste t-pareado superiores a 0,05 , indicaram séries estatisticamente semelhantes e, por conseguinte, ausência de influência significativa nas vazões do ribeirão Tortinho, enquanto, valores inferiores a 0,05 corresponderam a alterações significativas nas vazões do ribeirão.

\section{Modelo acoplado SWAT-MODFLOW}

O acoplamento dos modelos SWATMODFLOW possibilitou a modelagem integrada 
entre águas superficiais e subterrâneas possibilitando estudos e avaliação de impactos naturais e antropogênicos sobre os recursos hídricos com uma ampla gama de opções e flexibilidade no que diz respeito a modelagem (SOPHOCLEOUS et al.,1999; GUZMAN et al., 2015; KE, 2014).

No SWAT a simulação de processos relacionados às águas subterrâneas é realizada por modelo concentrado por sub-bacia, comum compartimento aquífero raso e um profundo, dificultando a distribuição espacial. Assim, o modelo SWAT não é preciso para a simulação de nível de aquíferos e de escoamento de base (PERKINS e SOPHOCLEOUS, 1999; WANG et al., 2013; SOPHOCLEOUS et al., 1999; Kim et al., 2008).

O MODFLOW consiste em um modelo de águas subterrâneas composto por rotinas para a simulação do fluxo de águas subterrâneas e a contínua interação rio-aquífero. Esse modelo não permite a especificação de processos hidrológicos superficiais da bacia e no perfil de solo e, por conseguinte, não simula com precisão taxas de recarga distribuída, que é essencial a modelagem de águas subterrâneas (PERKINS e SOPHOCLEOUS, 1999; WANG et al., 2013; SOPHOCLEOUS et al., 1999; KIM et al., 2008; KE, 2014).

Portanto, o SWAT-MODFLOW possibilita que as variações sazonais do nível freático e a recarga sejam distribuídos espacialmente e, logo, simulados com maior precisão do que quando se utiliza apenas o modelo de águas subterrâneas, além de se considerar o uso e práticas de gestão do solo, incluindo a simulação de culturas, lavouras e irrigação, na modelagem. Desse modo, o modelo acoplado é capaz de representar melhor os processos físicos da bacia (GUZMAN et al., 2015; SOPHOCLEOUS et al., 1999; SOPHOCLEOUS e PERKINS, 2000; PERKINS e SOPHOCLEOUS,1999).

\subsection{Dados de entrada e configuração do modelo SWAT-MODFLOW}

Em atendimento ao preconizado por Bailey e colaboradores (2017), foram usados os seguintes dados de entrada para modelagem com o SWATMODFLOW: shapes de sub-bacia, HRU e rio gerados pelo SWAT, o MDE, valores de condutividade hidráulica saturada, condutividade hidráulica do leito do rio, razão entre a condutividade hidráulica horizontal e vertical, carga hidráulica inicial, produção específica, armazenamento específico e a espessura do aquífero, dimensão desejada da célula da grade do MODFLOW, período de aquecimento e de simulação e a frequência de simulação tanto com o SWAT quanto com o MODFLOW. A preparação desses arquivos de entrada foi realizada com a interface SWATMOD-Prep (BAILEY et al., 2017).

De posse dos dados de entrada, foi possível desagregar as HRUs, criar a grade de células, identificar as células rio, além de gerar os arquivos de link entre as HRUs, DHRUs (HRU desagregada), sub-bacias do SWAT e a grade do MODFLOW com o SWATMOD-Prep. Como a interface permite apenas a criação de arquivos de entrada para modelos de uma camada (BAILEY et al., 2017), os seguintes arquivos foram modificados, após rodar o SWATMOD-Prep, para a inclusão de novas camadas no modelo:

- Modflow.bas: possui as informações de células ativas e valores de carga inicial.

- Modflow.dis: possui informações do modelo digital de elevação.

- Modflow.upw: contém os valores de condutividade hidráulica saturada, da relação entre a condutividade hidráulica horizontal e vertical, do armazenamento específico e da produção específica.

Após a modificação desses arquivos, o modelo acoplado SWAT-MODFLOW pôde ser executado para um modelo com o número de camada desejado, com suas características hidrogeológicas determinadas. Nesse trabalho, o SWAT foi executado em passo diário, porém com calibração e verificação mensal, o MODFLOW, em passo mensal, e os resultados apresentados em escala mensal.

\subsubsection{Modelo hidrogeológico conceitual}

O modelo hidrogeológico conceitual foi definido a partir do modelo digital de elevação (MDE), dados de perfil litológico dos poços na região (espessura do aquífero) e de nível do poço de monitoramento, disponibilizados pela ADASA, delimitação da bacia do ribeirão Tortinho, hidrografia, Mapa Geológico do Distrito Federal, shapes dos tipos de solos e do domínio fraturado.

A elaboração do modelo conceitual do aquífero considerou a caracterização do domínio poroso (FREITAS-SILVA e CAMPOS, 1998) e do domínio fraturado (GONÇALVES, 2012), além de ter sido realizado o espelhamento dos valores de espessura do aquífero para a região do PNB 
devido à ausência de dados.

A partir disso, delinearam-se a quantidade de camadas numéricas em cada domínio e seus MDE, a malha de diferenças finitas e as condições de contorno do modelo. Como condição de contorno, assumiu-se que o fluxo de água subterrâneo é nulo no divisor de água, ou seja, as células ativas se encontram dentro da delimitação da bacia. Já para a malha de diferenças finitas foram testados vários espaçamentos de grade de células até que o modelo convergisse, evitando a descontinuidade lateral entre células de mesma camada. Inicialmente, a célula da grade do MODFLOW foi definida com um tamanho de $150 \mathrm{~m}$, entretanto, foram testados novos tamanhos de célula para atingir os critérios de convergência na simulação.

Dessa forma, o modelo conceitual usado na simulação com o SWAT-MODFLOW foi construído com duas camadas geológicas (domínio poroso e fraturado), contendo duas camadas numéricas no domínio poroso e cinco no domínio fraturado, formadas a partir do MDE e dos dados de perfil litológico dos poços da região. A primeira camada do domínio poroso foi definida pelo MDE da superfície e pelo MDE em uma distância média entre a superfície e a rocha. Já a segunda camada do poroso se estendeu até a rocha.

No domínio fraturado, a primeira até a quarta camada foram delimitadas a partir do MDE do topo da rocha acrescido de 20,40, 60 e 80m em profundidade, enquanto a quinta camada do domínio fraturado foi considerada com elevação constante (com 10m de espessura imediatamente abaixo do rio), logo, a última camada possui espessura variável. As dimensões horizontais adotadas para a célula da grade do MODFLOW foi de $50 \mathrm{~m}$, gerando uma grade de 181 linhas e 210 colunas (Figura 7), necessárias à convergência do modelo.

Figura 7. Malha com célula de $50 \mathrm{~m}$ da área de estudo.

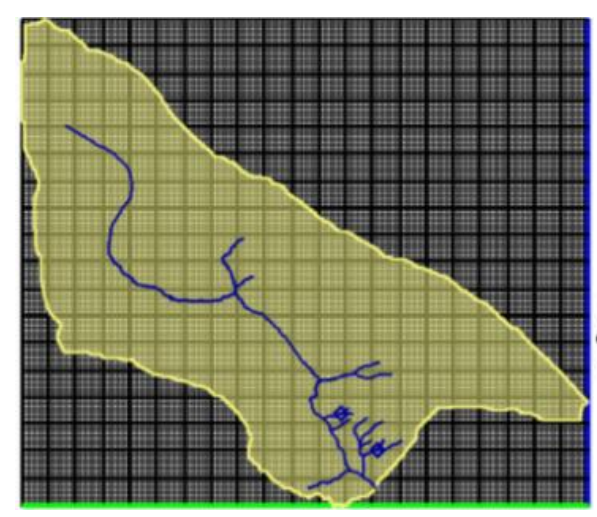

Fonte: Os autores.

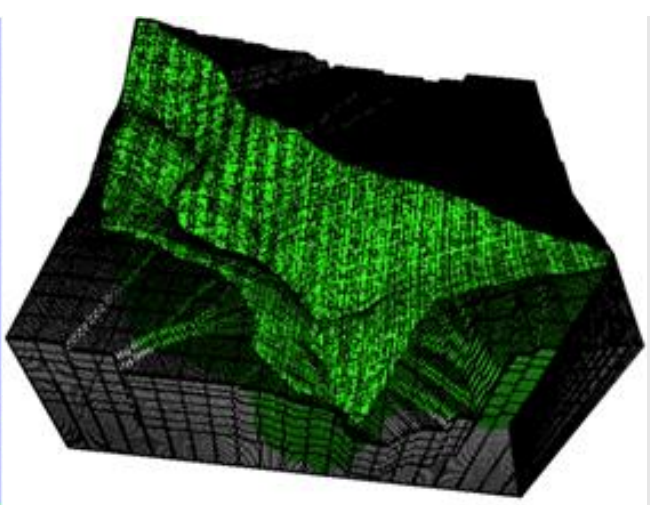

Em face a falta de dados de poços no Parque Nacional de Brasília (PNB), os dados de espessura do domínio poroso no LO foram espelhados para o PNB. Tendo em vista a presença de gleissolo na região abaixo do ribeirão Tortinho (Figura 4), caracterizado pela ocorrência de horizonte glei desfavorável a formação aquífera, devido a reduzida capacidade de drenagem e fluxo de água subterrânea (SANTOS et al., 2018), considerou-se uma profundidade de $0,5 \mathrm{~m}$ do domínio poroso logo abaixo do ribeirão Tortinho (Figura 8) de forma a representar o aquífero nas proximidades do ribeirão Tortinho por conta da contribuição do escoamento de base.

Já a direção e o ângulo de mergulho (35ํ) da Unidade Quartzito Médio (MNPpq3) foram definidos com base em Freitas-Silva e Campos

(1998). Ademais, assumiu-se a condição de contorno de Neumann com base no levantamento de nível dos poços rasos realizado em campo, no qual verificou-se a coincidência dos divisores de águas superficiais e águas subterrâneas.

\subsection{Calibração e Verificação do Modelo SWAT-MODFLOW}

A calibração do modelo acoplado SWATMODFLOW foi realizada manualmente, para o período de 1971 a 1975, modificando-se os valores de armazenamento específico (Ss), produção específica (Sy), condutividade hidráulica saturada (Ksat), razão entre a condutividade hidráulica horizontal e vertical $(\mathrm{Kh} / \mathrm{Kv})$, carga hidráulica inicial e condutividade hidráulica do leito do rio, que são parâmetros hidráulicos essenciais para simulação 
do fluxo subterrâneo. Já a verificação do modelo foi efetuada para o período de 1979 a 1984.

Para calibração do modelo acoplado SWATMODFLOW, inicialmente, foram adotados os parâmetros Ksat e Sy baseados em Santos e Koide (2016), Gonçalves (2012) e Campos e Freitas-Silva (1998), apresentados na Tabela 3.

Figura 8. Espessura do domínio poroso adotada para a bacia do ribeirão Tortinho.

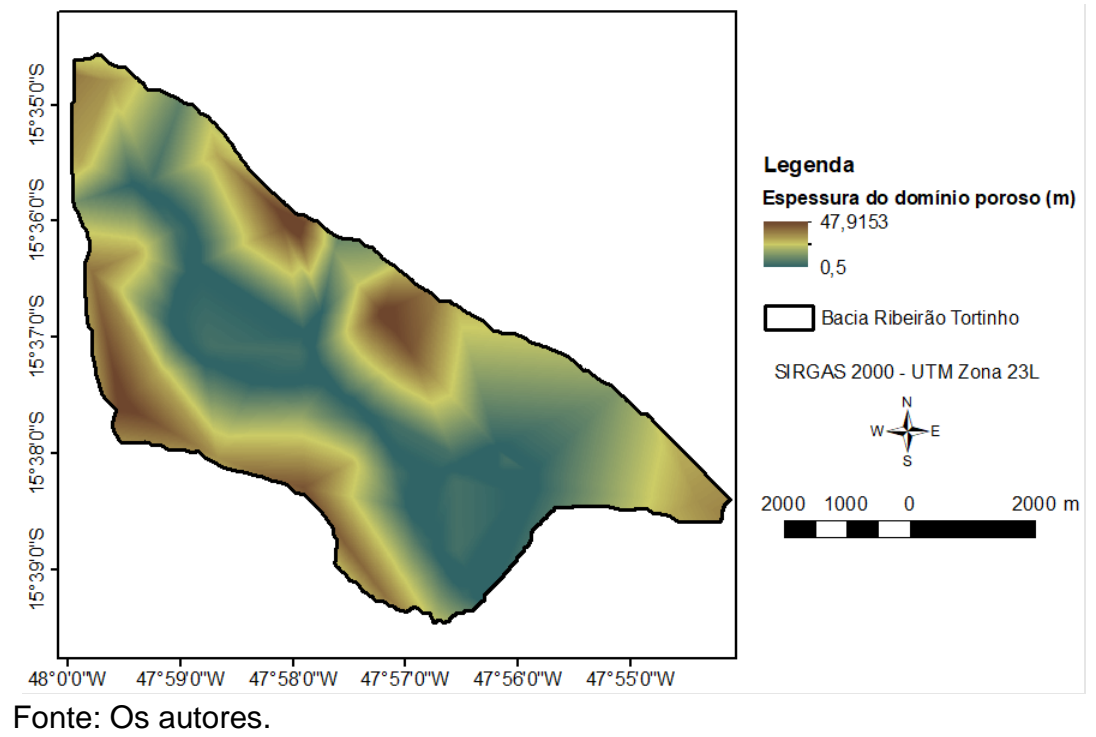

Os parâmetros Ksat, Sy, Kh/Kv e Ss foram definidos para as diferentes camadas geológicas e numéricas do modelo conceitual (Tabela 4). A carga hidráulica inicial, de $14,96 \mathrm{~m}$, foi definida com base no nível médio medido pela ADASA no poço de monitoramento 16, inserido na área do LO, para período semelhante ao início da simulação (época de chuva) e a condutividade hidráulica do leito do rio foi definida como $0,01 \mathrm{~m} / \mathrm{d}$.

Para a verificação do modelo, utilizaram-se os dados de vazão representativos da bacia do ribeirão Tortinho, conforme descrito no item 2.4, e os dados de nível do lençol freático, obtidos em levantamento nos poços rasos na região do LO.

Realizaram-se testes com diferentes períodos de calibração associados a distintos períodos de verificação devido à dificuldade de ajuste do modelo aos dados observados. A calibração do modelo acoplado SWAT-MODFLOW foi realizada para o período de 1971 a 1975 e a verificação para 1979 a 1984. Para efeitos de comparação com o modelo SWAT, optou-se por utilizar o mesmo período selecionado, tanto para a calibração quanto para a verificação.

Tabela 3. Valores iniciais de condutividade hidráulica saturada e produção específica usados.

\begin{tabular}{c|c|c|c}
\hline \multirow{3}{*}{ Domínio } & Solo/Unidade* & $\begin{array}{c}\text { Condutividade } \\
\text { Hidráulica Saturada - } \\
\text { Ksat (m/dia) }\end{array}$ & $\begin{array}{c}\text { Produção } \\
\text { específica - Sy } \\
\text { (adimensional) }\end{array}$ \\
\hline \multirow{4}{*}{ Poroso } & LV e LVA & 3,2220 & 0,089 \\
\cline { 2 - 4 } & $\mathrm{CX}$ & 0,5184 & 0,01 \\
\cline { 2 - 4 } & $\mathrm{FX}$ & 0,8989 & 0,01 \\
\cline { 2 - 4 } & $\mathrm{GX}$ & 0,0500 & 0,01 \\
\hline \multirow{3}{*}{ Fraturado } & $\mathrm{R} 4$ & 0,2450 & 0,014 \\
\cline { 2 - 4 } & $\mathrm{R} 3$ & 4,1550 & 0,12 \\
\cline { 2 - 4 } & $\mathrm{Q} 3$ & 7,2713 & 0,107 \\
\hline
\end{tabular}

*LV: Latossolo Vermelho; LVA: Latossolo Vermelho-Amarelo; CX: Cambissolo; GX: Gleissolo; R4: Unidade Metarritmito Argiloso; R3: Unidade Metarritmito Arenoso; Q3: Unidade Quartzito Médio. Fonte: Os autores. 
Tabela 4. Parâmetros utilizados no modelo acoplado SWAT-MODFLOW.

\begin{tabular}{|c|c|c|c|c|c|c|}
\hline \multicolumn{2}{|c|}{ Camadas } & \multirow{2}{*}{$\begin{array}{l}\text { Solo/ } \\
\text { Unidade }\end{array}$} & \multirow{2}{*}{$\begin{array}{l}\text { Condutividade } \\
\text { Hidráulica } \\
\text { Saturada - } \\
\text { Ksat (m/dia) }\end{array}$} & \multirow{2}{*}{$\begin{array}{c}\text { Produção } \\
\text { específica - Sy } \\
\text { (adimensional) }\end{array}$} & \multirow{2}{*}{$\begin{array}{c}\text { Relação } \\
\text { Kh/Kv }\end{array}$} & \multirow{2}{*}{$\begin{array}{c}\text { Armazenamento } \\
\text { específico -Ss } \\
(1 / \mathrm{m})\end{array}$} \\
\hline Geológicas & Numéricas & & & & & \\
\hline \multirow{4}{*}{ Poroso } & \multirow{4}{*}{1 e 2} & $\begin{array}{l}\text { LVe } \\
\text { LVA }\end{array}$ & 3,2220 & 0,089 & \multirow{4}{*}{0,1} & \multirow{4}{*}{$5 \times 10-4$} \\
\hline & & $\mathrm{CX}$ & 0,5184 & 0,01 & & \\
\hline & & FX & 0,8989 & 0,01 & & \\
\hline & & GX & 0,0500 & 0,01 & & \\
\hline \multirow{4}{*}{ Fraturado } & \multirow{3}{*}{$3,4,5$ e 6} & $\mathrm{R} 4$ & $2,45 \times 10-3$ & 0,014 & \multirow{4}{*}{1} & \multirow{4}{*}{$5 \times 10-5$} \\
\hline & & R3 & $4,1550 \times 10-2$ & 0,12 & & \\
\hline & & Q3 & $7,2713 \times 10-2$ & 0,107 & & \\
\hline & 7 & - & $10-5$ & $\begin{array}{c}\text { Igual as } \\
\text { camadas } 3,4, \\
5 \text { e } 6\end{array}$ & & \\
\hline & & $\mathrm{C}$ & hidr & $\begin{array}{l}\text { cial: } 14.96 \mathrm{~m} \\
\text { leito do rio: }\end{array}$ & $\mathrm{m} / \mathrm{d}$ & \\
\hline
\end{tabular}

Fonte: Os autores.

\subsection{Simulação de cenários com 0 modelo SWAT-MODFLOW}

Os cenários foram simulados para 1975 e 2013, considerando-se a exploração de águas subterrâneas sob diferentes condições de uso e cobertura do solo. A simulação dos cenários com poços compreendeu a avaliação de informações de poços cadastrados fornecidas pela ADASA, quanto a quantidade e tipo dos poços, vazão e tempo de bombeamento correspondente.

Os poços cadastrados cuja profundidade não correspondia ao tipo de poço informado (raso ou profundo) foram reclassificados quanto a sua profundidade. Poços indicados como manuais e com profundidade superior que $40 \mathrm{~m}$ foram reclassificados como tubulares, estando de acordo os resultados de levantamento de nível de poços rasos realizado em campo, no qual constatou-se que a profundidade máxima do domínio poroso está nessa faixa de valor na região. Aspectos construtivos, tais como o diâmetro do poço, escavação e revestimento, não foram considerados para a reclassificação dos poços devido à ausência de informação. Dessa maneira, a bacia do ribeirão Tortinho conta com 298 poços, sendo 91 poços manuais e 207 poços tubulares. A Tabela 5 apresenta uma síntese dos cenários simulados.

Tabela 5. Cenários simulados com o modelo SWAT-MODFLOW.

\begin{tabular}{l|c}
\hline Cenário & Descrição \\
\hline Teste & $\begin{array}{c}\text { Comparação entre a simulação com 233 poços manuais e } \\
\text { tubulares e 249 poços tubulares }\end{array}$ \\
\hline Cenário 0 & Sem poços \\
\hline Cenário 1 & 249 poços tubulares \\
\hline Cenário 2 & 496 poços tubulares \\
\hline Cenário 3 & 998 poços tubulares \\
\hline
\end{tabular}

Fonte: Os autores.

A simulação contendo todos os poços manuais apresentou erro de convergência em função do pequeno número de camadas verticais e, logo, secamento de poços no domínio poroso. Optou-se por não comprometer a resolução da malha xy e não aumentar o número de camadas verticais, que exigiria maior esforço computacional, além da alteração das vazões dos poços manuais com vazão superior à produção média do aquífero poroso, de $800 \mathrm{~m}^{3} / \mathrm{d}$ (FREITAS- 
SILVA e CAMPOS, 1998).

Na simulação do cenário teste, com os poços manuais e tubulares cadastrados pela ADASA, foram retirados 65 poços para que o modelo convergisse. Os poços retirados incluíam poços próximos ao divisor de águas superficiais e poços com vazões maiores que a vazão de produção média para o domínio poroso. Nesse cenário foram simulados 233 poços, dentre manuais e tubulares. A vazão retirada por esses 65 poços corresponde a $55,5 \%$ da vazão total prevista para os 298 poços outorgados na bacia.

Para simular o cenário de poços cadastrados pela ADASA considerando-se todos os poços da região como tubulares (cenário 1), foi necessário retirar 49 poços próximos ao divisor de águas para a convergência do modelo. Esse cenário possuía total de 249 poços tubulares. A vazão que seria retirada por esses 49 poços corresponde a 16,6\% da vazão total prevista para os 298 poços cadastrados na bacia.

Como no levantamento de nível de poços rasos observou-se que aproximadamente $53 \%$ dos poços não constavam na lista de poços manuais cadastrados fornecida pela ADASA, e para analisar o impacto do maior fracionamento das chácaras e do consumo de água sobre o fluxo de base, foram definidos os cenários 2 e 3 , com 0 intuito de tornar representativa a quantidade de poços, apesar de não haver como inferir os valores corretos de bombeamento, uma vez que não há medições.

O cenário 2 consistiu em dobrar a quantidade de poços tubulares e estimar a maior taxa de bombeamento possível para o aquífero conforme o modelo conceitual utilizado e a vazão média de produção para o aquífero fraturado, de $12000 \mathrm{~L} / \mathrm{h}$ (FREITAS-SILVA E CAMPOS, 1998), resultando em 496 poços tubulares e $7 \mathrm{~h}$ de bombeamento por dia.

Já no cenário 3 a quantidade de poços tubulares na região foi quadruplicada e a maior taxa de bombeamento possível para o aquífero foi estimada conforme o modelo conceitual utilizado e a vazão média de produção para o aquífero fraturado, 12000L/h (FREITAS-SILVA e CAMPOS, 1998), resultando em um total de 998 poços tubulares, quantidade escolhida por se aproximar a quantidade de chácaras na região do Núcleo Rural Lago Oeste, 1250 chácaras (Agência Câmara de Notícias , 2018), e frequência de bombeamento de 3,5 horas por dia.

\subsection{Avaliação da performance dos modelos (SWAT e SWAT-MODFLOW) e análises}

As análises da performance dos modelos foram realizadas quanto às métricas: coeficiente de determinação $\left(R^{2}\right)$, índice de eficiência NashSutcliffe (NSE) (NASH e SUTCLIFFE, 1970), Nash-sutcliffe do log das vazões (LogNSE) e viés (PBIAS) (GUPTA et al., 1999). Todas as métricas obtidas com o resultado da simulação usando o SWAT foram calculadas diretamente pelo SWATCUP, exceto o LogNSE, que foi calculado com o pacote R "hydroGOF" (ZAMBRANO-BIGIARINI, 2013) e as métricas relacionadas aos resultados da simulação com o modelo acoplado SWATMODFLOW também foram calculadas com o pacote R "hydroGOF".

O coeficiente de determinação $\left(R^{2}\right)$ indica a colinearidade existente entre os dados simulados e observados. O valor desse coeficiente pode variar de 0 a 1 , sendo que quanto mais próximo de 1 menor será a variância do erro. Valores acima de 0.5 são considerados aceitáveis/satisfatórios segundo Moriasi et al. (2007).

O índice de eficiência Nash-Sutcliffe (NSE) varia de $-\infty$ a 1 compara a variância residual com a variância dos dados observados. Valores negativos indicam que a média prevê melhor do que os valores simulados, portanto, a performance do modelo não é aceitável enquanto valores positivos são aceitáveis, sendo que, de acordo com Moriasi et al. (2007) a performance é satisfatória quando o valor de NSE é maior que 0.50. O NSE é a função objetivo que melhor descreve, de forma geral, o ajuste de um hidrograma, porém ele apresenta dificuldades em descrever as vazões mínimas e é sensível aos picos de vazão (SERVAT e DEZETTER,1991, KRAUSE et al., 2005; ALTHOFF e RODRIGUES, 2021).

Segundo Krause et al. (2005) e Althoff e Rodrigues (2021), o índice de eficiência NashSutcliffe logarítmico (LogNSE), que é calculado com o logaritmo dos valores de vazão observada e simulada, reduz a sensibilidade do NSE aos valores extremos e a aumenta para valores menores permitindo um melhor ajuste para os períodos de recessão do hidrograma.

$O$ viés (PBIAS) indica se os dados simulados estão superestimados (PBIAS positivo) ou subestimados (PBIAS negativo). Valores de PBIAS com baixa magnitude indicam acurácia na simulação, sendo que, o valor ótimo do PBIAS é 
zero (GUPTA et al., 1999; ALTHOFF e RODRIGUES, 2021).

Maiores detalhes a respeito das métricas utilizadas nesse trabalho podem ser encontrados no estudo de Althoff e Rodrigues (2021).

\section{RESULTADOS E DISCUSSÃO}

\subsection{Simulação, Calibração e Verificação do modelo SWAT}

A simulação inicial realizada com o modelo SWAT, sem calibração, não representou adequadamente a vazão observada (NSE $=-0,15$, $\left.R^{2}=0,43\right)$. De modo geral, vazões de pico foram superestimadas e o fluxo de base foi subestimado (Figura 9).

A Tabela 6 apresenta os testes para a calibração e verificação do modelo, utilizando diferentes períodos de dados, bem como os valores das métricas (NSE, LogNSE, $\mathrm{R}^{2}$ e PBIAS) para os períodos analisados. Na primeira etapa de testes para a calibração, o período que apresentou melhor ajuste foi de 1971 a 1975 (Cal1), com melhor desempenho em todas as métricas quando comparado com os períodos de 1971 a 1978 (Cal2) e 1975 a 1978 (Cal3), ou seja, com maiores valores de NSE, LogNSE, $R^{2}$ e PBIAS mais próximo de zero (Tabela 6).

Figura 9. Hidrograma observado e simulado com o modelo SWAT sem calibração para o período de 1971 a 1986.

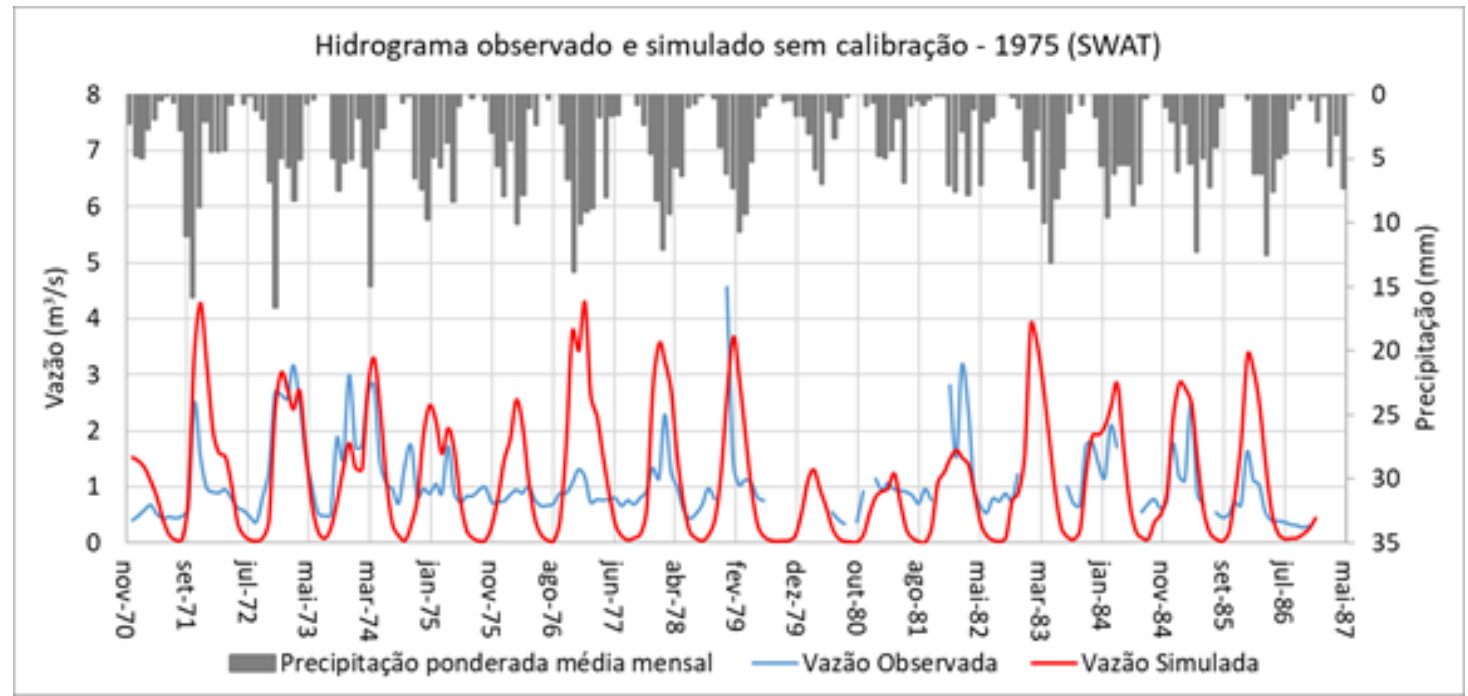

Fonte: Os autores.

Em seguida, para a verificação utilizando os parâmetros calibrados (Cal1), o melhor ajuste foi obtido no período de 1979 a 1984 (Ver_e). Entretanto, como os valores obtidos para as métricas utilizadas são insatisfatórios quanto a performance do modelo, de acordo com Moriasi et al. (2007), realizou-se uma segunda etapa de testes incluindo 5 anos no processo de calibração e verificação (Tabela 7).

Durante os processos de calibração e verificação, observou-se que, a inclusão dos dados obtidos entre os anos de 1976 e 1978, acarretou impacto negativo nas métricas de performance do modelo (Tabela 6), indicando, provavelmente, problemas quanto à medição dos dados hidrológicos, mau funcionamento da estação ou então anos atípicos, que não representaram a série de dados. Portanto, na segunda etapa de calibração, esses anos foram excluídos da série visando melhorar o ajuste aos dados, porém o desempenho do modelo foi pior do que o período selecionado na primeira etapa (Tabela 6 e Tabela 7).

Logo, após as duas etapas de testes, o período de 1971 a 1975 (Cal1) foi selecionado para a calibração mensal do modelo $\left(\mathrm{NSE}=0,48, \mathrm{R}^{2}=\right.$ 0,48). Para a verificação, o período de 1979 a 1984 (Ver_e) foi selecionado (NSE $=0,31$ e $R^{2}=0,40$ ). Nos períodos selecionados o modelo apresentou melhor performance e, portanto, foi capaz de se ajustar e representar os dados observados. O hidrograma apresentado na Figura 10 mostra a série de dados observados e simulados após a calibração (Cal1) e verificação (Ver_e) do modelo para os anos de 1971 a 1986. 
Tabela 6. Períodos testados para calibração e verificação do modelo SWAT na bacia do ribeirão Tortinho.

\begin{tabular}{|c|c|c|c|}
\hline \multicolumn{2}{|c|}{ Calibração } & \multicolumn{2}{|c|}{ Verificação } \\
\hline Período & Métricas & Período & Métricas \\
\hline \multirow{5}{*}{ Cal1: 1971 a 1975} & \multirow{5}{*}{$\begin{array}{c}\mathrm{NSE}=0.48 \\
\operatorname{LogNSE}=0.47 \\
\mathrm{R}^{2}=0.48 \\
\mathrm{PBIAS}=0.90\end{array}$} & Ver_a: 1976 a 1986 & $\begin{array}{c}\mathrm{NSE}=-0.70 \\
\operatorname{LogNSE}=-0.98 \\
\mathrm{R}^{2}=0.00 \\
\mathrm{PBIAS}=-7.0\end{array}$ \\
\hline & & Ver_b: 1976 a 1980 & $\begin{array}{c}\mathrm{NSE}=-0.40 \\
\operatorname{LogNSE}=-0.28 \\
\mathrm{R}^{2}=0.13 \\
\text { PBIAS }=-33.7\end{array}$ \\
\hline & & Ver_c: 1976 a 1978 & $\begin{array}{c}\mathrm{NSE}=-2.77 \\
\operatorname{LogNSE}=-1.50 \\
\mathrm{R}^{2}=0.32 \\
\text { PBIAS }=-46.0\end{array}$ \\
\hline & & Ver_d: 1976 a 1979 & $\begin{array}{c}\mathrm{NSE}=-0.48 \\
\operatorname{LogNSE}=-0.56 \\
\mathrm{R}^{2}=0.10 \\
\text { PBIAS }=-34.5\end{array}$ \\
\hline & & Ver_e: 1979 a 1984 & $\begin{array}{c}\mathrm{NSE}=0.31 \\
\log \mathrm{NSE}=0.04 \\
\mathrm{R}^{2}=0.4 \\
\text { PBIAS }=-20.80\end{array}$ \\
\hline \multirow{2}{*}{ Cal2: 1971 a 1978} & \multirow{2}{*}{$\begin{array}{c}\mathrm{NSE}=0.37 \\
\mathrm{LogNSE}=0.34 \\
\mathrm{R}^{2}=0.38 \\
\mathrm{PBIAS}=-3.5\end{array}$} & Ver_f: 1979 a 1984 & $\begin{array}{c}\mathrm{NSE}=-0.45 \\
\operatorname{LogNSE}=-1.68 \\
\mathrm{R}^{2}=0.02 \\
\mathrm{PBIAS}=40.2\end{array}$ \\
\hline & & Ver_g: 1979 a 1985 & $\begin{array}{c}\mathrm{NSE}=-0.46 \\
\operatorname{LogNSE}=-1.51 \\
\mathrm{R}^{2}=0.00 \\
\text { PBIAS }=35.4\end{array}$ \\
\hline Cal3: 1975 a 1978 & $\begin{array}{c}\mathrm{NSE}=0.19 \\
\mathrm{LogNSE}=0.09 \\
\mathrm{R}^{2}=0.28 \\
\mathrm{PBIAS}=-9.6\end{array}$ & Ver_h: 1971 a 1974 & $\begin{array}{c}\mathrm{NSE}=0.18 \\
\log \mathrm{NSE}=0.34 \\
\mathrm{R}^{2}=0.47 \\
\text { PBIAS }=-21.4\end{array}$ \\
\hline
\end{tabular}

Fonte: Os autores.

Tabela 7. Períodos testados em uma segunda etapa para a calibração e verificação do modelo SWAT na bacia do ribeirão Tortinho.

\begin{tabular}{|c|c|c|c|}
\hline \multicolumn{2}{|c|}{ Calibração } & \multicolumn{2}{|c|}{ Verificação } \\
\hline Período & & Período & \\
\hline $\begin{array}{c}\text { Cal4: } 1971 \text { a } \\
1984\end{array}$ & $\begin{array}{c}\mathrm{NSE}=0.042 \\
\operatorname{LogNSE}=-0.11 \\
\mathrm{R}^{2}=0.09 \\
\mathrm{PBIAS}=1.5\end{array}$ & Ver_i: 1985 a 1990 & $\begin{array}{c}\mathrm{NSE}=0.029 \\
\operatorname{LogNSE}=-0.06 \\
\mathrm{R}^{2}=0.08 \\
\text { PBIAS }=0.6\end{array}$ \\
\hline $\begin{array}{c}\text { Cal5: } 1971 \text { a } \\
\text { 1984, exceto os } \\
\text { anos } 1976 \text { a } \\
1978\end{array}$ & $\begin{array}{c}\mathrm{NSE}=0.19 \\
\log N S E=0.12 \\
\mathrm{R}^{2}=0.19 \\
\mathrm{PBIAS}=3.0\end{array}$ & Ver_j: 1985 a 1990 & $\begin{array}{c}\mathrm{NSE}=-0.013 \\
\operatorname{LogNSE}=-0.10 \\
\mathrm{R}^{2}=0.07 \\
\text { PBIAS }=7.6\end{array}$ \\
\hline
\end{tabular}

Fonte: Os autores. 
Figura 10. Hidrograma observado e simulado com o SWAT com calibração ao longo de 1971 a 1986.

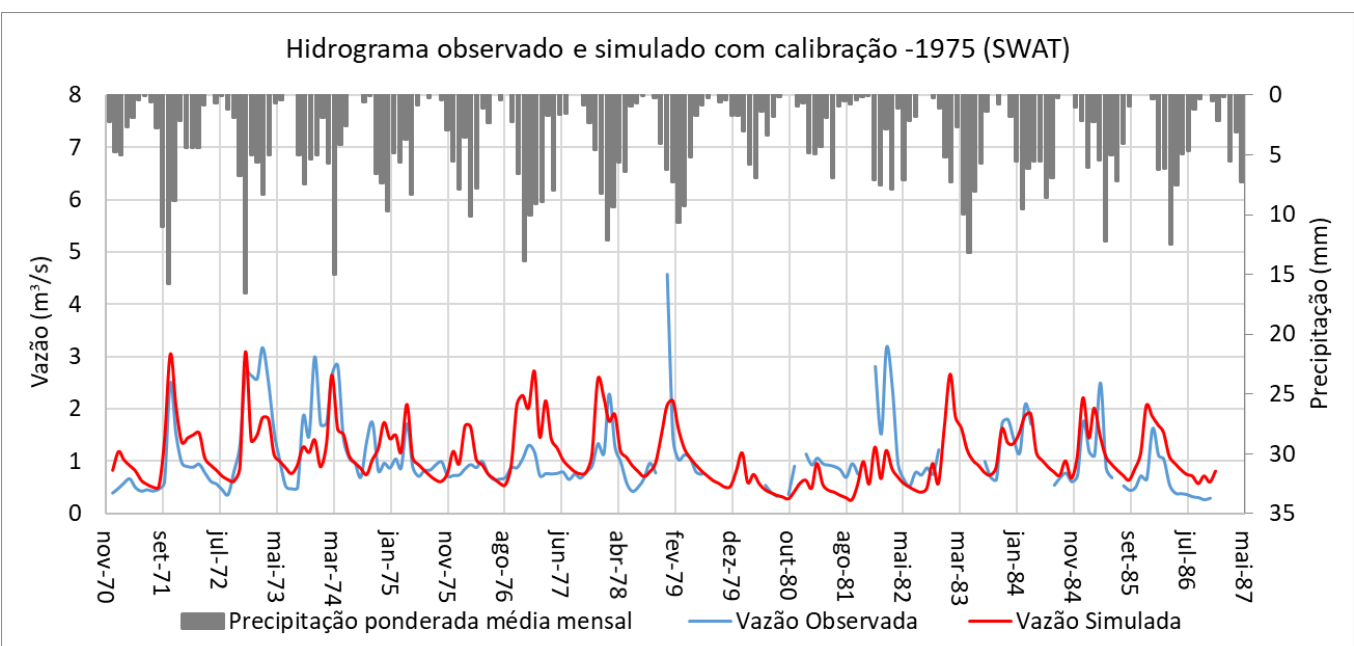

Fonte: Os autores.

Considerando a necessidade de verificar 0 ajuste dos dados simulados aos períodos de recessão, avaliou-se o desempenho do modelo por meio da métrica LogNSE. O período selecionado também apresentou melhor ajuste quando comparado a outros períodos testados, entretanto, ainda assim, o modelo apresentou performance insatisfatória, segundo Moriasi et al. (2007).

Tal nível de ajuste aos dados observados, apesar dos diversos testes de calibração, pode ser resultado das incertezas associadas às vazões observadas devido à influência do remanso na estação fluviométrica utilizada e de possíveis problemas quanto aos equipamentos de medição. Outro fator que provavelmente influenciou os resultados obtidos, foi a análise de consistência utilizada para os dados fluviométricos. Conforme Reitz e Dias (2014), o método de análise de consistência escolhido para os dados fluviométricos de estações instáveis, que sofrem influência de remanso, pode ter impacto significativo, como verificado em seu estudo, no qual houve uma diferença de $36 \%$ nos valores obtidos de Q90, comparando-se a aplicação do método simplificado e do método do desnível normal. Já Rolim et al. (2020) utilizaram um método simplificado, que consiste em um modelo estatístico, para calibrar a curva-chave de vazão do rio Tapajós, que também sofre com o efeito do remanso obtendo-se um coeficiente de correlação múltipla igual a 0,9454 e o coeficiente de NashSutcliffe igual a 0,8938 .

Devido ao posto fluviométrico utilizado no presente trabalho estar em um local de acesso restrito, dentro de um Parque Nacional, não foi possível montar uma seção de controle e realizar o monitoramento complementar. Portanto, este estudo também reflete a importância da localização adequada da seção de controle, fora do alcance dos efeitos do remanso, monitoramento e manutenção adequados das estações e equipamentos, além de mão de obra qualificada para a realização das medições e instalações.

Ademais, ao longo do processo de calibração também se observou que a interface do SWATCUP, para os parâmetros calibrados pelo método multiplicativo, libera apenas um valor ajustado, porém, quando se compara os arquivos de backup com os arquivos da calibração realizada pode-se observar que os parâmetros apresentam valores diferentes daqueles dados na interface. Assim, os valores dos parâmetros foram recalculados $e$, no caso dos parâmetros SOL_K(..).sol, SOL_AWC.sol, SOL_BD(..).sol, foi considerada cada camada de solo já que o valor multiplicado é diferenciado por camada. A Tabela 8 mostra o método e os valores ajustados para cada um dos parâmetros para a bacia do ribeirão Tortinho mediante calibração com a interface SWAT-CUP para o período selecionado (calibração: 1971 a 1975 e verificação: 1979 a 1984).

\subsection{Avaliação da influência do uso e cobertura do solo sobre a vazão do ribeirão Tortinho}

Após seleção dos melhores períodos para a calibração e verificação e, por conseguinte, conclusão das simulações, compararam-se os resultados dos cenários de pré-urbanização (1975) e urbanização (2013) calibrados (Figura 11). Os 
resultados da comparação não indicaram mudanças significativas na série de vazões em decorrência da alteração na cobertura do solo, apesar das mudanças na extensão da área do Núcleo Rural Lago Oeste que corresponde a aproximadamente $21,6 \%$ da área da bacia.

Tabela 8. Valores ajustados para os parâmetros calibrados para o período de 1971 a 1975.

\begin{tabular}{|c|c|c|c|}
\hline \multicolumn{4}{|c|}{ Parâmetros, métodos e valores da calibração para a bacia do ribeirão Tortinho. } \\
\hline Parâmetros & Unidade & Método & Valor ajustado* \\
\hline \multirow{3}{*}{ SOL_K(..).sol } & \multirow{3}{*}{$\mathrm{mm} / \mathrm{h}$} & \multirow{3}{*}{ multiplicativo } & C1 0,798291 \\
\hline & & & C2 0,798295 \\
\hline & & & C3 0,798272 \\
\hline \multirow{3}{*}{ SOL_AWC.sol } & \multirow{3}{*}{$\mathrm{mm} / \mathrm{mm}$} & \multirow{3}{*}{ multiplicativo } & C1 0,5000 \\
\hline & & & C2 0,35714 \\
\hline & & & C3 0,35714 \\
\hline \multirow{3}{*}{ SOL_BD(..).sol } & \multirow{3}{*}{$\mathrm{g} / \mathrm{cm}^{3}$} & \multirow{3}{*}{ multiplicativo } & C1 0,7647 \\
\hline & & & C2 0,044444 \\
\hline & & & C3 0,044444 \\
\hline DEEPST.gw & $\mathrm{mm}$ & substitutivo & 11,506059 \\
\hline GW_REVAP.gw & adimensional & substitutivo & 0,095693 \\
\hline GWHT.gw & $\mathrm{mm}$ & substitutivo & 23,260632 \\
\hline RCHRG_DP.gw & $\mathrm{mm}$ & substitutivo & 0,025368 \\
\hline GW_DELAY.gw & dias & aditivo & 199,2217 \\
\hline GWQMN.gw & $\mathrm{mm}$ & substitutivo & 1073,5846 \\
\hline REVAPMN.gw & $\mathrm{mm}$ & substitutivo & 191,94324 \\
\hline SHALLST.gw & $\mathrm{mm}$ & substitutivo & 3593,0432 \\
\hline ESCO.hru & adimensional & substitutivo & 0,910349 \\
\hline EPCO.bsn & adimensional & substitutivo & 0,241715 \\
\hline ANION_EXCL.sol & adimensional & multiplicativo & 0,56944 \\
\hline CN2.mgt & adimensional & multiplicativo & 0,191147 \\
\hline SURLAG.bsn & dias & substitutivo & 4,718503 \\
\hline OV_N.hru & adimensional & multiplicativo & 0,6454067 \\
\hline
\end{tabular}

${ }^{*} \mathrm{C} 1$ = camada $1, \mathrm{C} 2$ = camada $2, \mathrm{C} 3$ = camada 3

Fonte: Os autores.

Figura 11. Hidrograma observado e simulado calibrado para os uso e cobertura do solo relativos aos anos de 1975 e 2013.

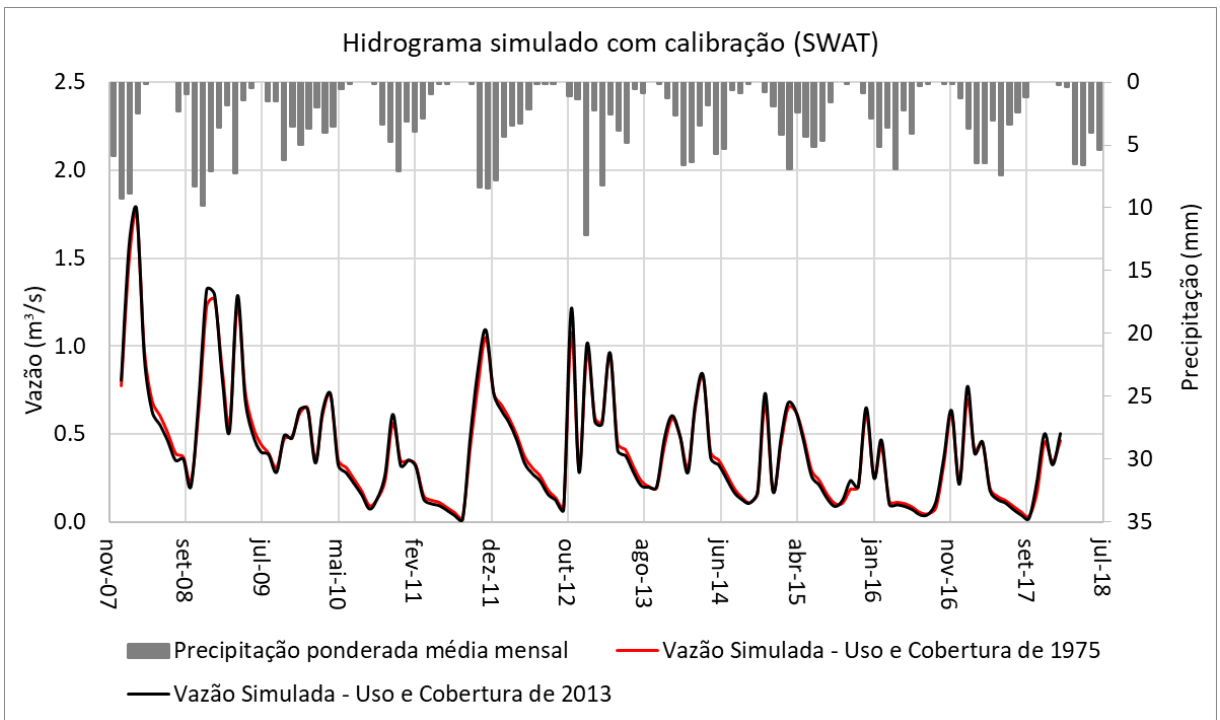

Fonte: Os autores. 
Tanto para o período de seca quanto para o período chuvoso, o teste t-pareado bilateral apresentou um valor $p$ superior a 0,05 , indicando que as médias para as séries simuladas com os cenários de uso e cobertura de 1975 e 2013 são estatisticamente semelhantes. Portanto, o impacto da alteração do uso e cobertura do solo ocorrida entre 1975 e 2013 não afetou significativamente as vazões do ribeirão Tortinho.

Apesar de não indicar diferenças significativas, houve redução de $8,5 \%$ na média da vazão para o período seco (escoamento de base), entre 1975 e 2013. Em contrapartida, no período chuvoso se verificou um aumento de $4,8 \%$ na média no hidrograma simulado, considerando a média dos valores acumulados mensais dos anos de 2013 a 2017.

\subsection{Calibração e Verificação do modelo acoplado SWAT-MODFLOW}

A calibração do SWAT-MODFLOW foi efetuada para o período de 1971 a 1975 resultando em um NSE igual a 0,43, LogNSE e $R^{2}$ iguais a 0,49. Já na verificação, de 1979 a 1984, obteve-se um NSE de 0,42, LogNSE de 0,43 e $\mathrm{R}^{2}$ igual a 0,50 indicando um melhor ajuste quanto aos períodos de recessão. No entanto, o modelo representa insatisfatoriamente a situação real, segundo Moriasi (2007). Devido às dificuldades no processo de ajuste na calibração manual, há incertezas quanto aos valores dos parâmetros selecionados, sendo possível que os valores obtidos de condutividade hidráulica estejam baixos. A Figura 12 mostra as vazões simuladas, calibradas e o fluxo de base para os períodos de 1971 a 1986 e 2008 a 2018.

Figura 12. Hidrograma observado, simulado e fluxo de base para o modelo acoplado SWAT-MODFLOW durante o período de (a) 1971 a 1986 e (b) 2008 a 2018.

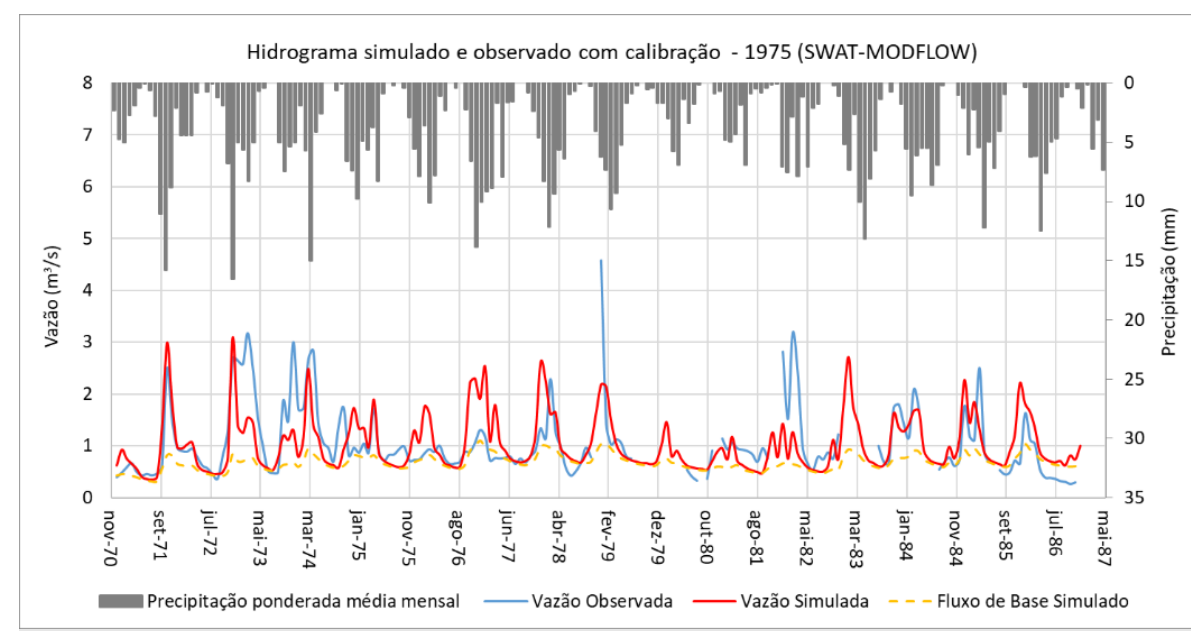

(a)

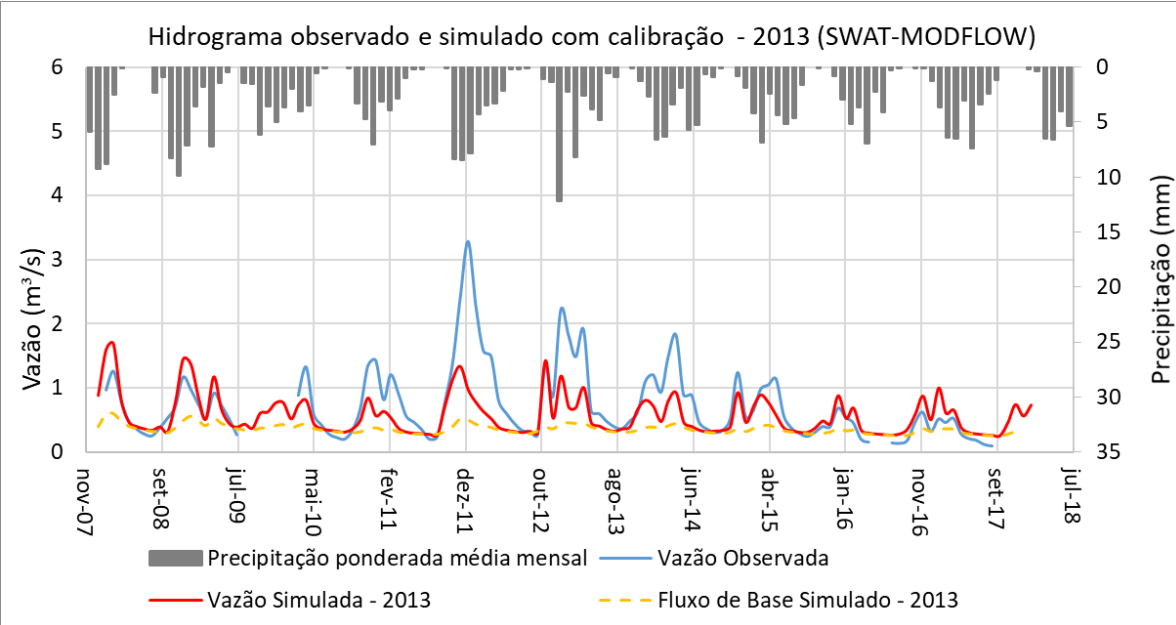

Fonte: Os autores. 


\subsection{Cenarização com poços na bacia do ribeirão Tortinho}

Os cenários de teste, simulados considerando 233 poços manuais e tubulares e 249 poços tubulares, não apresentaram diferenças significativas, bem como em relação ao cenário sem poços (cenário zero) (Figura 13). Isso se deve ao fato de que a vazão dos poços retirados representa, em média 0,7 e 2,4\% da média mensal da vazão observada, respectivamente, para 0 cenário com poços manuais e tubulares e para o cenário com poços tubulares. Assim, a configuração com 249 poços tubulares foi adotada também para os cenários seguintes.

Nos cenários sem poços e com poços cadastrados pela ADASA pode-se observar uma subestimativa das vazões simuladas com relação as vazões observadas. Comparando-se a vazão específica da bacia de estudo com a vazão específica da bacia do Rodeador, próxima e com características hidrogeológicas semelhantes, para os períodos de recessão (junho a setembro) nos anos de 1978 a 1988 (período com baixa atividade antrópica em ambas as bacias) verificou-se valores em torno de $45 \%$ maiores para a vazão específica do ribeirão Tortinho. Tal discrepância pode ser resultado dos problemas relatados pela CAESB citados anteriormente (item 2.4), indicando a necessidade de melhorar as medições fluviométricas.

A Figura 14 presenta o rebaixamento provocado no hidrograma na simulação do cenário 2 com 496 poços tubulares e $84 \mathrm{~m}^{3} / \mathrm{d}$ por poço, junto com o cenário 1 , com 249 poços tubulares, com vazão e taxa de bombeamento cadastrados pela ADASA.

A Figura 15 mostra o rebaixamento provocado no hidrograma na simulação do cenário 3, com 998 poços tubulares e $42 \mathrm{~m}^{3} / \mathrm{d}$ por poço, junto com o cenário 1, com 249 poços tubulares, com vazão e taxa de bombeamento cadastrados pela ADASA. A vazão total retirada no cenário 1 atingiu um percentual máximo de $6,3 \%$ da vazão do ribeirão Tortinho e mínimo de 0,6\%. Enquanto, nos cenários 2 e 3 o percentual máximo foi de $146,7 \%$ da vazão média observada do ribeirão Tortinho e mínimo de 13,3\%, sendo que o percentual máximo ocorreu para o ano hidrológico de outubro de 2016 a setembro de 2017 , enquanto o mínimo ocorreu para outubro de 2006 a setembro de 2007.

Figura 13. Hidrograma observado e simulado para o modelo sem poços, com 249 poços tubulares e com 233 poços manuais e tubulares.

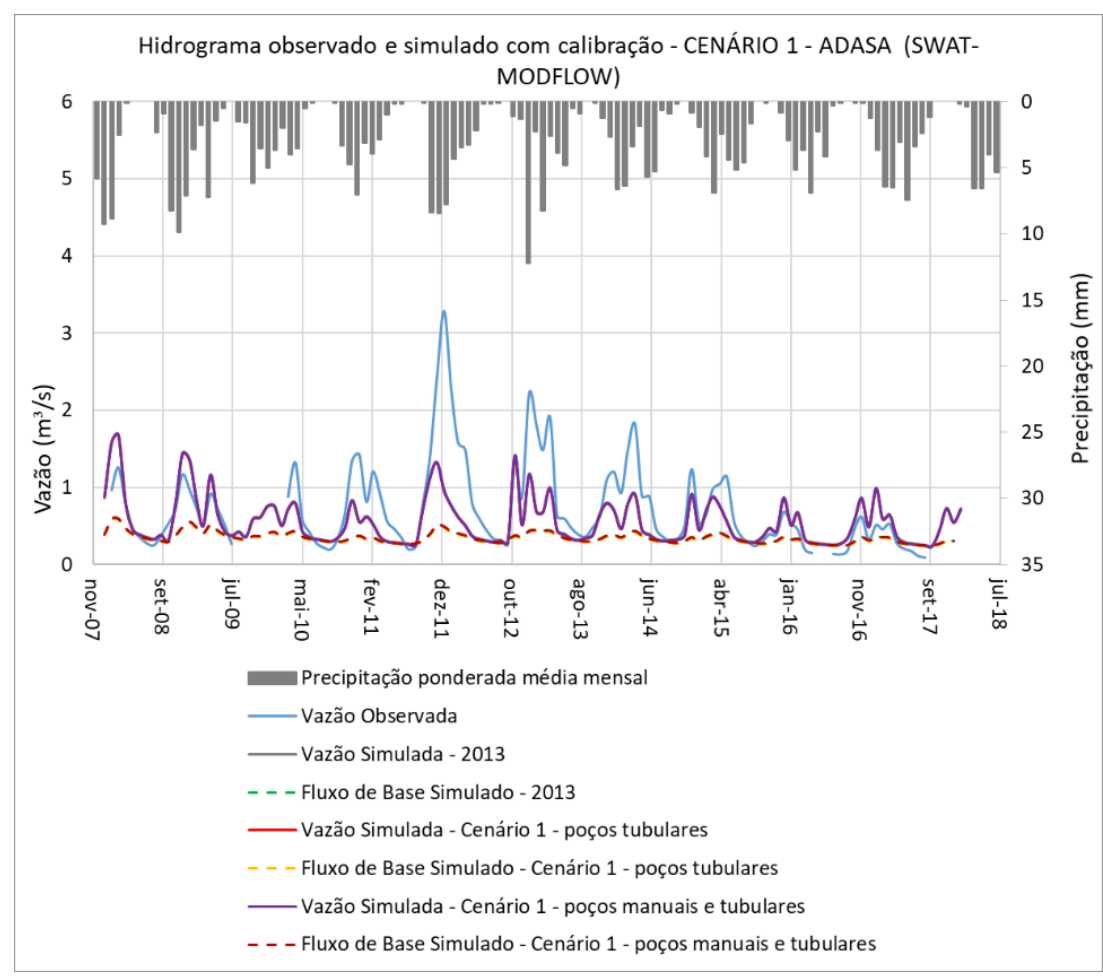

Fonte: Os autores. 
Figura 14. Hidrograma observado e simulado para os cenários 1 e 2.

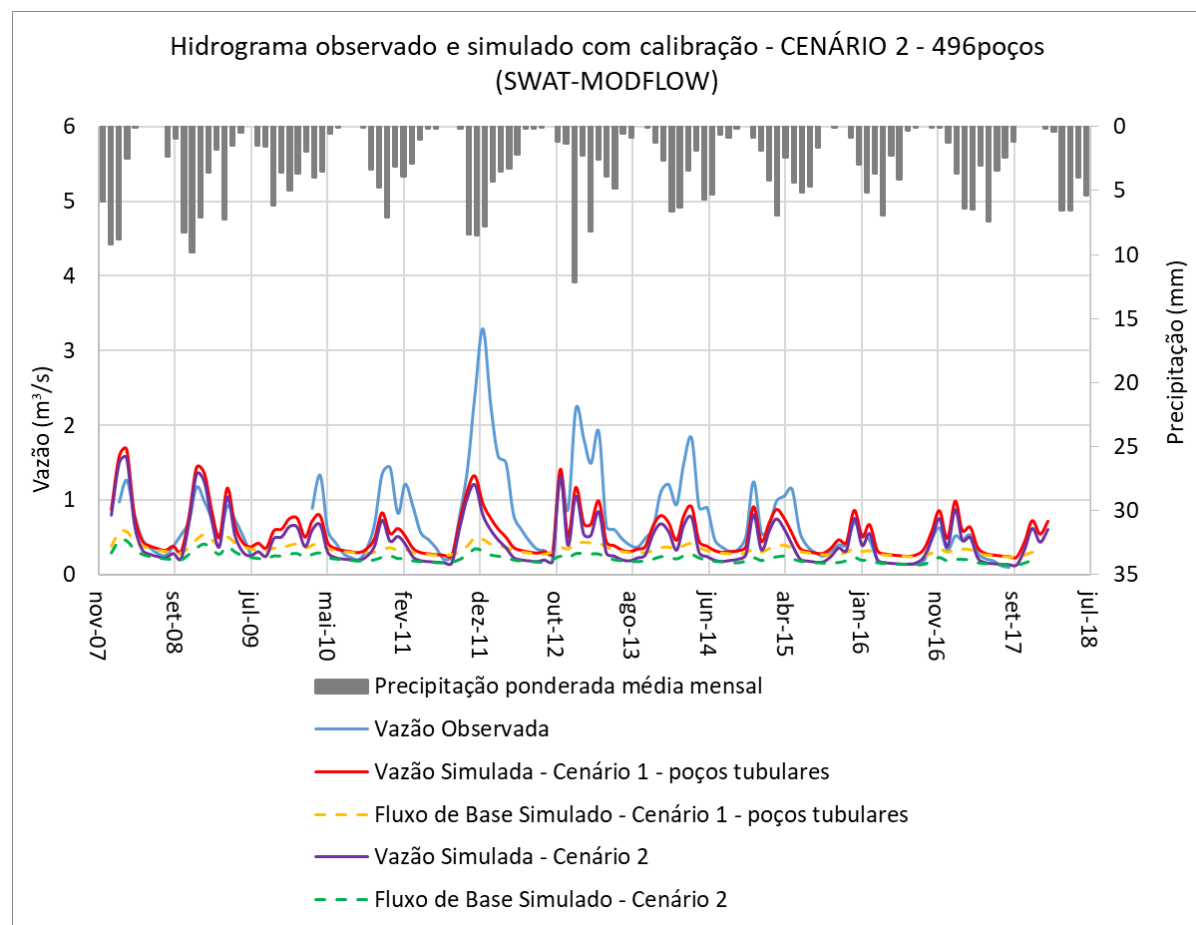

Fonte: Os autores.

Figura 15. Hidrograma observado e simulado para os cenários 1 e 3.

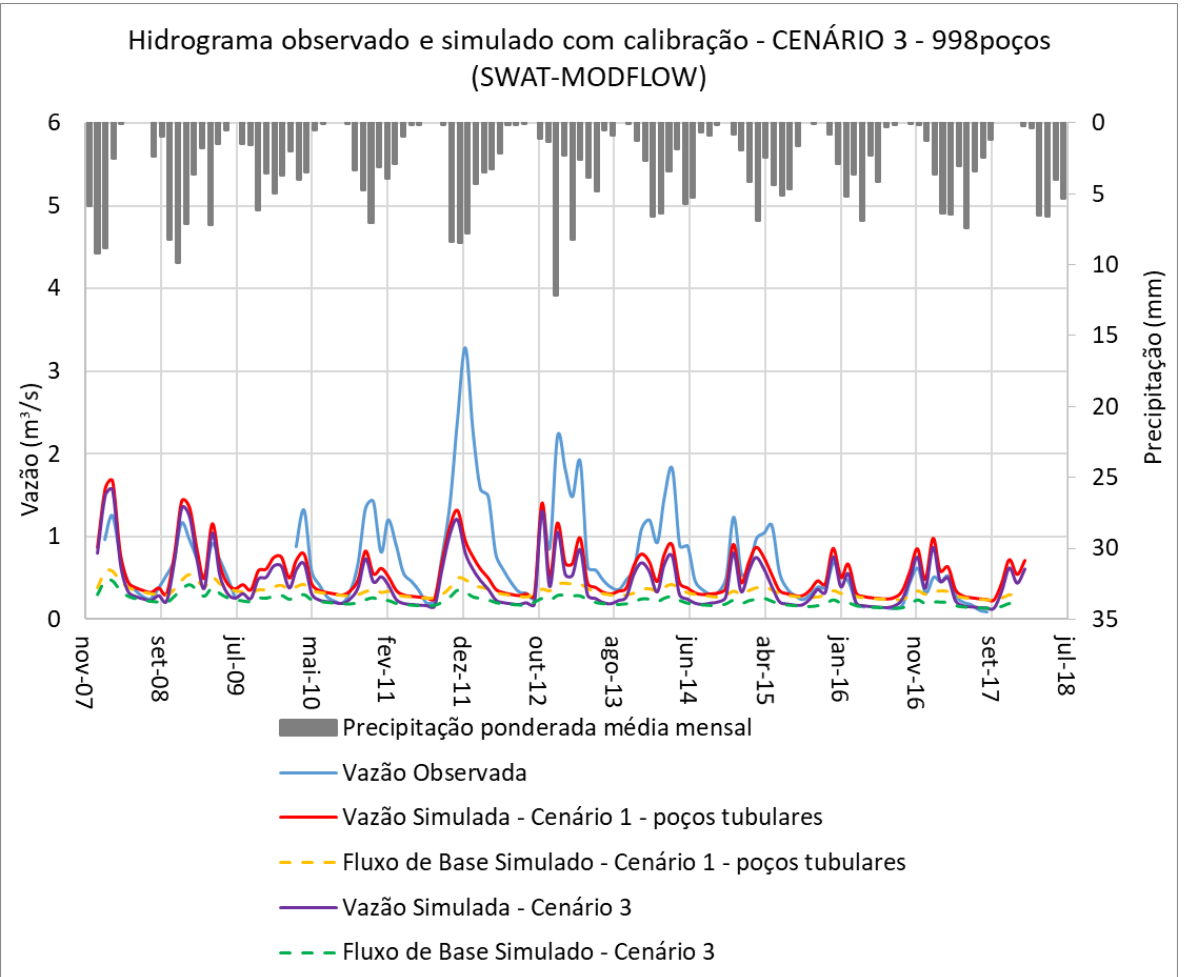

Fonte: Os autores.

A Tabela 9 apresenta o volume total de fluxo de base ao longo dos anos hidrológicos para a simulação sem poços e os valores obtidos para os cenários 1,2 e 3 . Houve redução do volume do fluxo de base simulado, além do fato que a inserção dos poços para a extração de águas 
subterrâneas nos cenários simulados contribuiu significativamente para a diminuição do volume total de fluxo de base anual.

A diminuição percentual média do fluxo de base para o cenário 1 foi maior no ano hidrológico de outubro de 2008 a setembro de 2009, com um valor de 39\%. e menor no ano hidrológico de outubro de 2016 a setembro de 2017, com um rebaixamento médio percentual de 19\% (Tabela 10). Já os cenários 2 e 3 apresentaram maior diminuição percentual no ano hidrológico de outubro de 2009 a setembro de 2010, com aproximadamente $57 \%$ de redução no fluxo de base.

Na Tabela 10 também é apresentada a porcentagem da vazão escoada que essa diminuição no fluxo de base representa em cada um dos cenários quando comparado com a simulação sem poços. No ano hidrológico de outubro de 2009 a setembro de 2010, a diminuição do fluxo de base causada pelo bombeamento de água subterrânea pelos poços no cenário 1 representa $29 \%$ da vazão escoada na bacia e para o ano hidrológico de outubro de 2016 a setembro de 2017 a diminuição do fluxo de base correspondeu a $13 \%$ da vazão escoada, sendo o menor valor dentre os anos simulados. Para os cenários 2 e 3 , o fluxo de base correspondeu a maior porcentagem da vazão escoada para o ano hidrológico de outubro de 2010 a setembro de 2011, sendo igual a 46\%, respectivamente, enquanto a menor porcentagem se deu para o ano hidrológico de outubro de 2016 a setembro de 2017, de $34 \%$.

Diante desses resultados, é necessário ressaltar que há uma percentagem significativa de redução do fluxo de base proveniente da simulação dos três cenários.

Tabela 9. Volume total anual de fluxo de base simulado.

\begin{tabular}{l|l|l|l|l}
\hline & \multicolumn{4}{|c}{ Fluxo de base acumulado anual (mm/ano) } \\
\hline Ano Hidrológico & sem poços & Cenário 1 & Cenário 2 & Cenário 3 \\
\hline out/08 a set/09 & 508,47 & 308,52 & 223,93 & 223,77 \\
\hline out/09 a set/10 & 434,49 & 272,68 & 188,03 & 187,71 \\
\hline out/10 a set/11 & 353,35 & 228,58 & 153,04 & 152,70 \\
\hline out/11 a set/12 & 383,53 & 274,96 & 181,31 & 180,94 \\
\hline out/12 a set/13 & 370,00 & 276,71 & 181,22 & 180,66 \\
\hline out/13 a set/14 & 341,05 & 259,36 & 166,43 & 165,76 \\
\hline out/14 a set/15 & 314,69 & 245,88 & 155,13 & 154,33 \\
\hline out/15 a set/16 & 269,65 & 213,22 & 131,15 & 130,35 \\
\hline out/16 a set/17 & 274,16 & 222,38 & 136,26 & 135,39 \\
\hline
\end{tabular}

Fonte: Os autores.

Tabela 10. Redução percentual média do fluxo de base e porcentagem da vazão escoada que a redução do fluxo de base representa para os cenários 1, 2 e 3 .

\begin{tabular}{|c|c|c|c|c|c|c|}
\hline & \multicolumn{3}{|c|}{ Redução percentual média do fluxo de base } & \multicolumn{3}{|c|}{$\begin{array}{l}\text { Percentagem da vazão escoada que a redução } \\
\text { do fluxo de base representa }\end{array}$} \\
\hline Ano Hidrológico & Cenário 1 & Cenário 2 & Cenário 3 & Cenário 1 & Cenário 2 & Cenário 3 \\
\hline out/08 a set/09 & $39 \%$ & $56 \%$ & $56 \%$ & $28 \%$ & $40 \%$ & $40 \%$ \\
\hline out/09 a set/10 & $37 \%$ & $57 \%$ & $57 \%$ & $29 \%$ & $44 \%$ & $44 \%$ \\
\hline out/10 a set/11 & $35 \%$ & $57 \%$ & $57 \%$ & $29 \%$ & $46 \%$ & $46 \%$ \\
\hline out/11 a set/12 & $28 \%$ & $53 \%$ & $53 \%$ & $19 \%$ & $36 \%$ & $36 \%$ \\
\hline out/12 a set/13 & $25 \%$ & $51 \%$ & $51 \%$ & $17 \%$ & $34 \%$ & $35 \%$ \\
\hline out/13 a set/14 & $24 \%$ & $51 \%$ & $51 \%$ & $17 \%$ & $37 \%$ & $37 \%$ \\
\hline out/14 a set/15 & $22 \%$ & $51 \%$ & $51 \%$ & $16 \%$ & $36 \%$ & $36 \%$ \\
\hline out $/ 15$ a set/16 & $21 \%$ & $51 \%$ & $52 \%$ & $16 \%$ & $39 \%$ & $39 \%$ \\
\hline out/16 a set/17 & $19 \%$ & $50 \%$ & $51 \%$ & $13 \%$ & $34 \%$ & $34 \%$ \\
\hline
\end{tabular}

Fonte: Os autores. 
A Figura 16 apresenta a carga simulada na primeira camada numérica do domínio poroso da bacia do ribeirão Tortinho sem poços para 0 período de novembro de 2008. A ocorrência de células secas (sem valor), representadas por áreas brancas na figura, próximas ao ribeirão Tortinho, se deve provavelmente a pequena espessura atribuída ao domínio poroso logo abaixo do rio.

A Figura 17(a) apresenta a carga para a primeira camada, os poços cadastrados pela ADASA e os poços retirados na simulação do cenário 1. Observa-se uma área de secamento (células sem valor) na primeira camada do domínio poroso próximo ao divisor de bacia, além de que, comparando-se com a simulação sem poços também já se pode reparar um rebaixamento da carga. A Figura 17(b) apresenta a carga para a quinta camada numérica do modelo considerando o cenário 1 e o período de novembro de 2008.
Nos cenários 2 (Figura 18) e 3 Figura 19) observa-se uma extensa área de secamento no domínio poroso, ao longo da primeira camada, em toda região do LO prolongando-se ainda até próximo ao ribeirão Tortinho, nos locais onde o domínio poroso é mais fino, dentro do PNB, podendo afetar a vegetação nativa em vista ao baixo suprimento hídrico disponível, ressalta-se que, o secamento do domínio poroso ao longo do LO foi verificado em campo e ocorre atualmente devido a exploração de águas subterrâneas no local. Portanto, a gestão e fiscalização quanto a exploração de águas subterrâneas na região é de fundamental importância e pode ser realizada por meio da instalação de hidrômetros nos poços, segundo o Decreto 22018/01.

$\mathrm{Na}$ quinta camada desses cenários também se torna evidente o rebaixamento da carga no domínio fraturado.

Figura 16. Carga simulada para a primeira camada numérica do domínio poroso para a simulação sem poços para novembro de 2008 na bacia do ribeirão Tortinho.

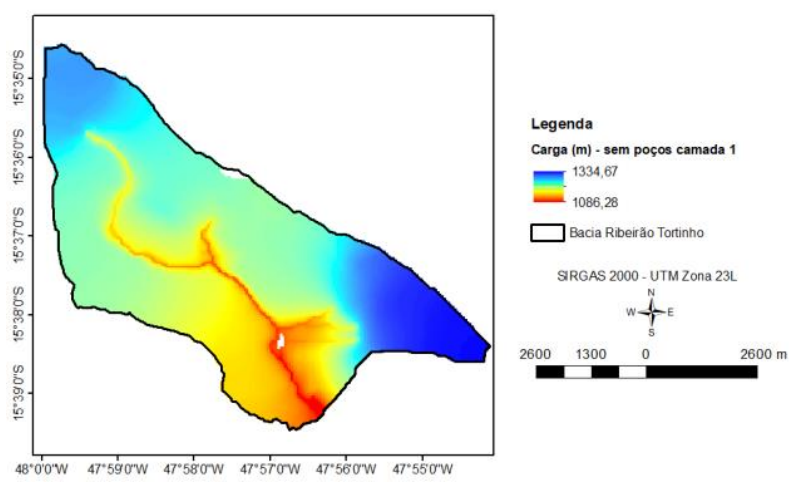

Fonte: Os autores.

Figura 17. Carga simulada para o cenário 1 na (a) primeira camada numérica (domínio poroso) e (b) quinta camada numérica (domínio fraturado) para novembro de 2008 na bacia do ribeirão Tortinho.

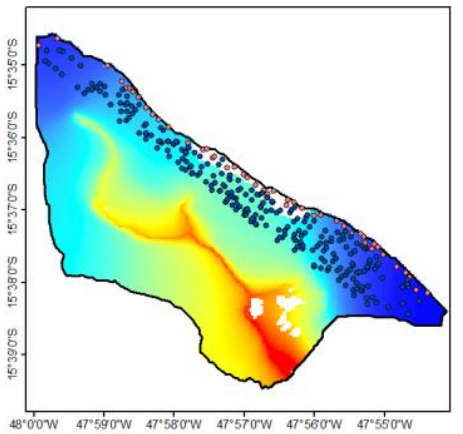

Fonte: Os autores.

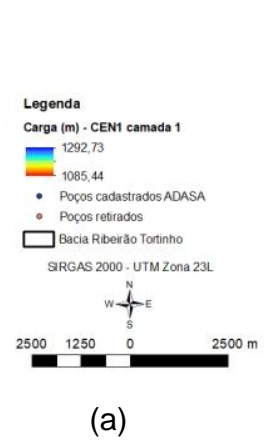

(a)
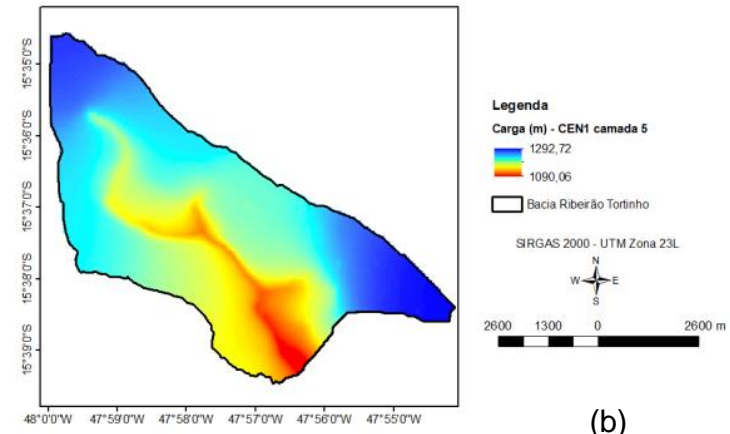

(b) 
Figura 18. Carga simulada para o cenário 2 na (a) primeira camada numérica (domínio poroso) e (b) quinta camada numérica (domínio fraturado) para novembro de 2008 na bacia do ribeirão Tortinho.
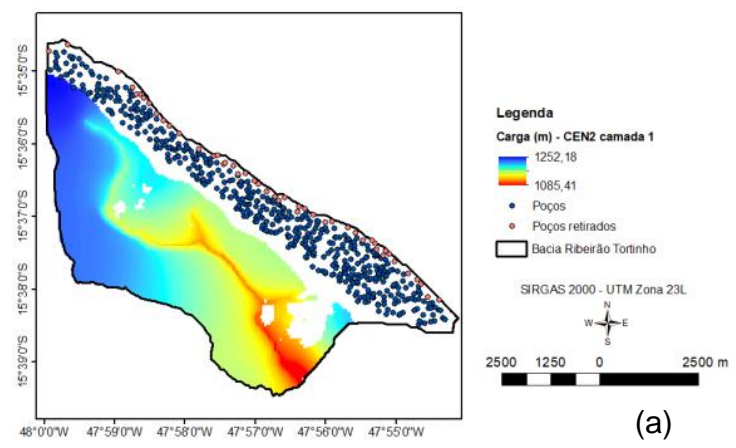

(a)

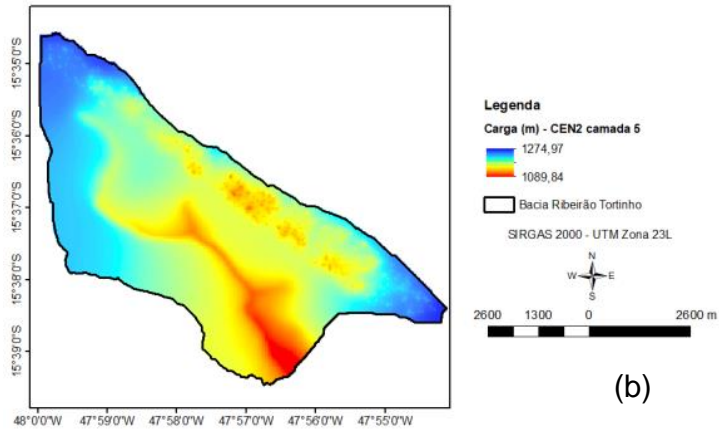

(b)

Fonte: Os autores.

Figura 19. Carga simulada para o cenário 3 na (a) primeira camada numérica (domínio poroso) e (b) quinta camada numérica (domínio fraturado) para novembro de 2008 na bacia do ribeirão Tortinho.
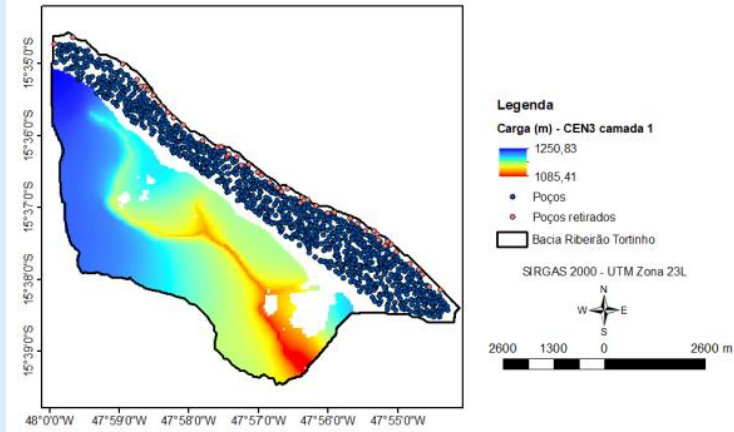

Fonte: Os autores

O corte transversal ao longo da bacia e passando pelo ribeirão Tortinho foi realizado na coluna 65 e linha 80 da grade de células ativas do MODFLOW (Figura 20), para avaliar a carga. $O$ modelo conceitual adotado não foi capaz de simular a carga de forma adequada, provavelmente, devido à pouca discretização na malha vertical. Segundo Gao (2011), condições complexas na geologia e hidrogeologia podem acarretar oscilações numéricas e, logo, instabilidade na solução da equação de fluxo ao se utilizar o método de diferenças finitas, como o MODFLOW. Alguns exemplos dessas condições são: mudanças bruscas na topografia, forte gradiente hidráulico, condições de retirada de água do aquífero e/ou múltiplos aquíferos com fluxos em direções diferentes devido a estresses no aquífero. Ademais, Gao (2011) aponta a necessidade da construção de um modelo refinado já que a discretização espacial possibilita a simulação da complexidade da hidrogeologia local.

No caso desse estudo, observa-se mudanças de topografia na bacia (Figura 20). Adicionalmente, (a)

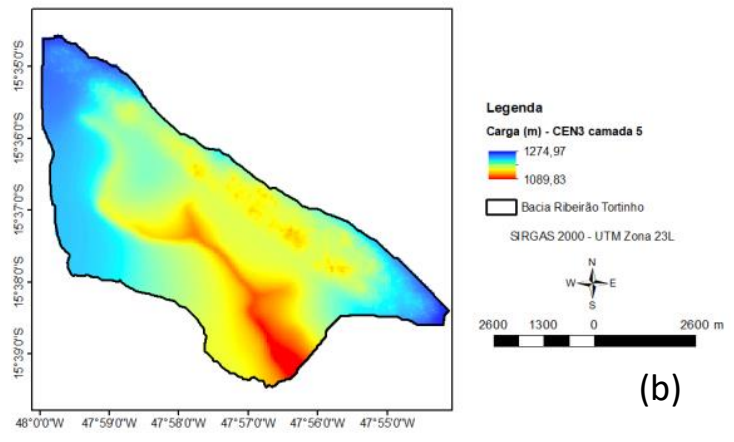

pelo fato de a grade do modelo ser plana, há uma distorção por causa da topografia pois quando o gradiente hidráulico é calculado pelo modelo, há uma componente em $Z$ que não é levada em conta, podendo contribuir para valores elevados de carga. A condição de contorno adotada, bem como a consideração da isotropia e da homogeneidade dos aquíferos também pode ter influenciado no resultado de carga.

Células de observação foram alocadas na quinta camada numérica do modelo (na qual há a retirada de água) em locais nos quais foi realizado o levantamento de dados de nível em poços rasos em campo, no ponto de monitoramento da ADASA no 16 e na cabeceira do ribeirão Tortinho com o intuito de verificar os valores simulados de carga. O modelo utilizado está superestimando a carga observada nos pontos analisados (Figura 21). A superestimativa das cargas se dá, provavelmente, pela propagação dos erros e incertezas associados aos dados de vazão observados e utilizados na calibração do modelo, como citado no item 2.3. 
Figura 20. Cortes ao longo da coluna 65 (A-A' em azul) e linha 80 (B-B' em verde) da malha de diferenças finitas na bacia do ribeirão Tortinho para novembro de 2008.

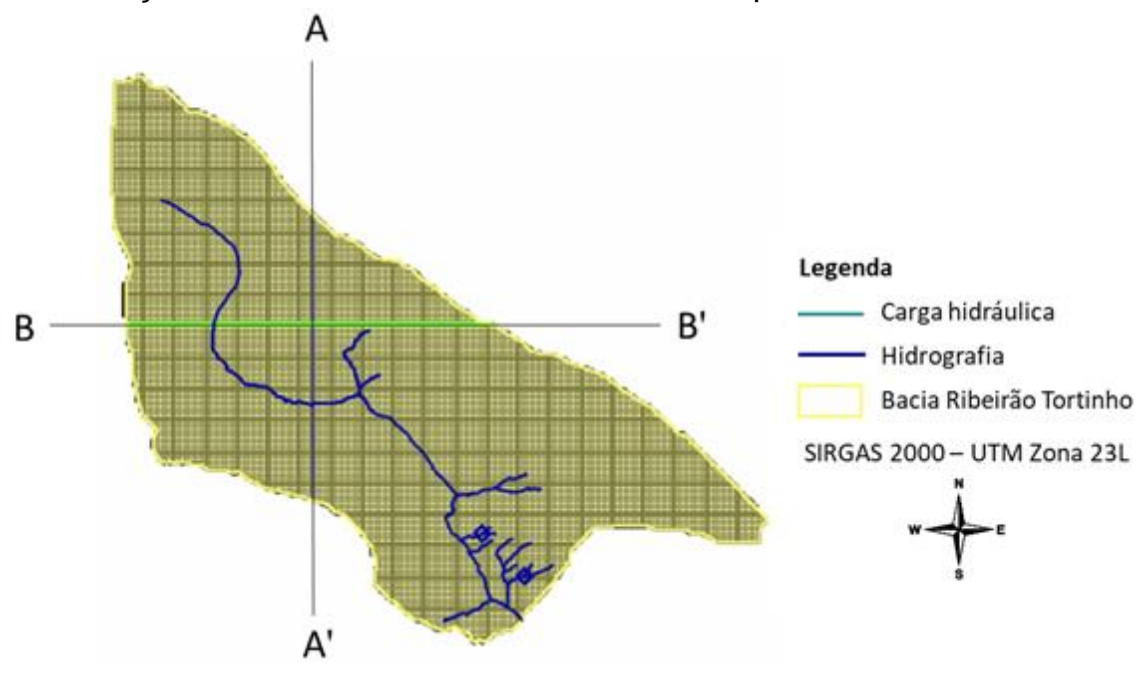

A

B $\quad$ B
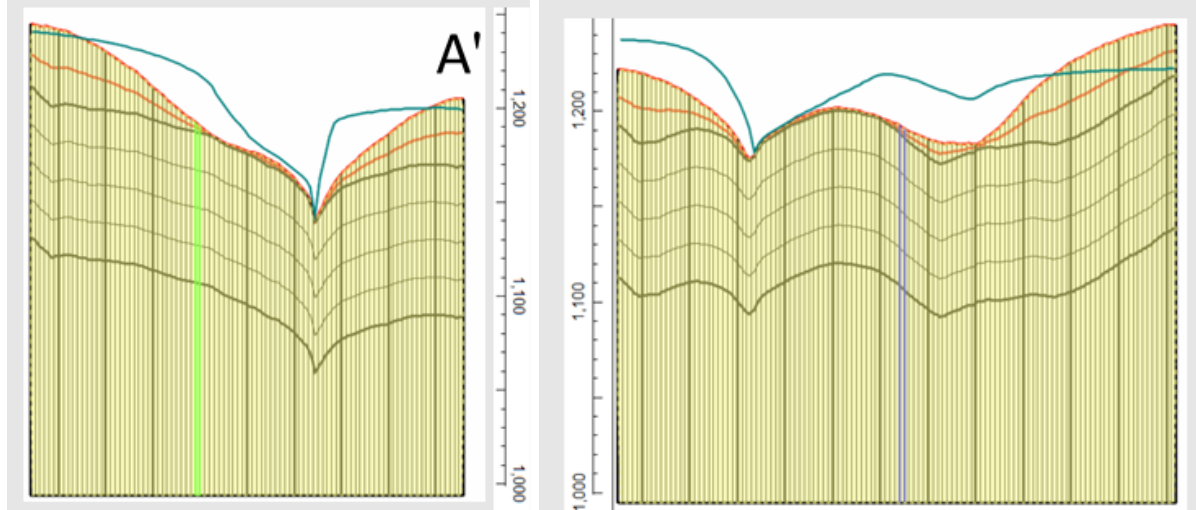

Fonte: Os autores.

Figura 21. Gráfico de valores observados vs valores simulados para os pontos de observação inseridos no modelo.

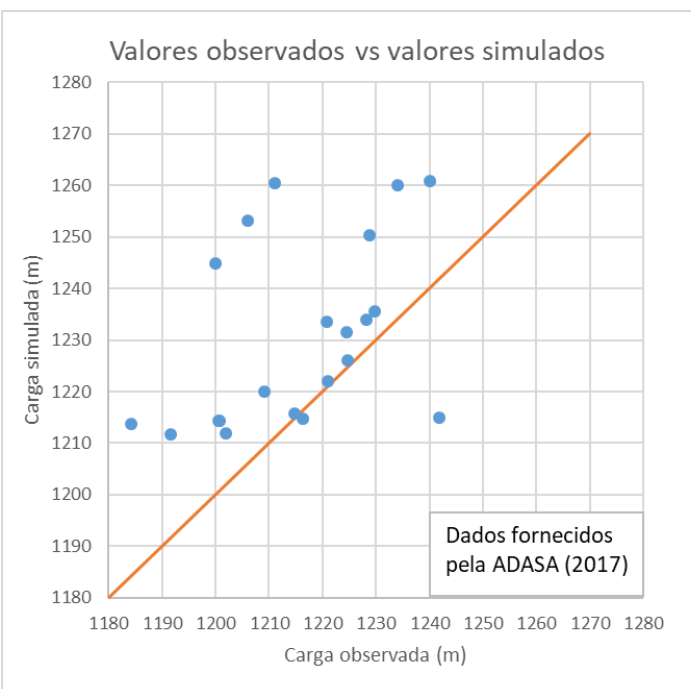

Fonte: Os autores 


\section{CONCLUSÕES E RECOMENDAÇÕES}

O estudo forneceu uma análise preliminar da influência da urbanização e da retirada de águas sobre a vazão do ribeirão Tortinho, apesar das limitações associadas aos dados de vazão na área de estudo. As simulações com o modelo SWAT não indicaram influência significativa das alterações da cobertura do solo na vazão do ribeirão Tortinho, apesar dos resultados indicarem tendência de redução no escoamento de base, durante o período de seca, e incremento no escoamento superficial, durante a estação chuvosa. Aliado ao panorama hidrológico resultante da expansão da ocupação urbana e agrícola na bacia do ribeirão Tortinho, a aplicação do modelo ressaltou a importância da qualidade dos dados de entrada para a construção de modelos que possam representar adequadamente os processos hidrológicos de bacia.

O ajuste insatisfatório aos dados observados, apesar das diferentes tentativas de calibração e verificação, ocorreu provavelmente devido às incertezas associadas as vazões observadas, tanto em decorrência da estação fluviométrica utilizada que sofre influência do remanso quanto a possíveis problemas nos equipamentos de medição. Sendo assim, este estudo reflete a importância da localização e manutenção adequadas das estações e equipamentos de monitoramento, assim como, da mão de obra qualificada para a realização das instalações e medições de modo que os dados a serem utilizados como subsídio para a modelagem tenham qualidade e possam contribuir de maneira efetiva e eficiente para o processo de gestão e tomada de decisão quanto aos recursos hídricos.

As simulações efetuadas com o modelo acoplado SWAT-MODFLOW apontam que a exploração de águas subterrâneas no LO pode afetar de forma significativa a posição do lençol freático no domínio poroso, inclusive no Parque Nacional de Brasília podendo trazer consequências à vegetação nativa. Apesar de haver uma superestimativa da carga quanto à simulação com o modelo SWAT-MODFLOW, é possível realizar uma análise qualitativa da situação e verificar que há necessidade de se controlar e fiscalizar a extração de águas subterrâneas da região, por meio da hidrometração de poços conforme o Decreto 22018/01.

Mesmo dentre todas as limitações do trabalho foi possível analisar qualitativa e preliminarmente a região de estudo de forma a balizar ações com relação à gestão dos recursos hídricos. Tais limitações do trabalho englobam: a interferência do remanso sobre a estação fluviométrica utilizada, a carência de dados fluviométricos, ausência de dados de captação e retirada difusa de água do rio, sendo viável utilizar apenas essa única estação para esse trabalho.

Recomenda-se que, para futuros trabalhos seja realizada:

- Uma análise de consistência mais cuidadosa e criteriosa dos dados fluviométricos da estação Torto-Granja, aplicando-se diferentes métodos, por exemplo, como realizado nos estudos de Reitz e Dias (2014) e de Rolim et al. (2020).

- A definição de parâmetros correlacionando-os às características da bacia, além de analisar os dados e parâmetros de forma a identificar problemas no ajuste dos valores simulados aos valores observados.

- A análise mais aprofundada sobre a operação da barragem localizada à jusante da estação fluviométrica TortoGranja e suas influências sobre a medição de vazão.

- A revisão do posicionamento da estação fluviométrica para que a influência do remanso seja mitigada e as medições futuras sejam mais precisas.

\section{AGRADECIMENTOS}

À CAPES, pela concessão da bolsa de mestrado, à UnB, ANA, FAPDF, FINEP, FINATEC e FUNAPE pelo apoio à execução da pesquisa a que o trabalho está vinculado.

\section{REFERÊNCIAS}

ABBASPOUR, K. C. SWAT-CUP: SWAT Calibration and Uncertainty Programs - A User Manual. Eawag, 100p., $2015 . \quad$ Disponível em: https://swat.tamu.edu/media/114860/usermanual swatc up.pdf

AGÊNCIA CÂMARA NOTÍCIAS. Órgãos federais e do DF avaliarão processo de licenciamento ambiental de núcleo rural. Câmara dos Deputados, 2018. Disponível em: https://www.camara.leg.br/noticias/550044-orgaosfederais-e-do-df-avaliarao-processo-de-licenciamentoambiental-de-nucleo-rural/. 
ALTHOFF, D.; RODRIGUES, L. N. Goodness-of-fit criteria for hydrological models: Model calibration and performance assessment. Journal of Hydrology, v. 600, 2021. Disponível em: https://doi.org/10.1016/j.jhydrol.2021.126674.

ARNOLD, J. G.; SRINIVASAN, R.; MUTTIAH, R. S.; WILLIAMS, J. R. Large area hydrologic modeling and assessment part I: Model development. Journal of the American Water Resources Association, v. 34, n. 1, p. 1-17, 1998. Disponível em: https://doi.org/10.1111/j.1752-1688.1998.tb05961.x

ARNOLD, J.G.; MORIASI, D. N.; GASSMAN, P.W.; ABBASPOUR, K. C.; WHITE, M.J.; SRINIVASAN, R.; SANTHI, C.; HARMEL, D.; VAN GRIENSVEN, A.; VAN LIEW, M. W.; KANNAN, N.; JHA, M. K. SWAT: Model use, calibration, and validation. Biological Systems Engineering: Papers and Publications, 406, 2012. Disponível em: https://digitalcommons.unl.edu/cgi/viewcontent.cgi?artic le=1408\&context=biosysengfacpub.

BAILEY, R.; RATHJENS, H.; BIEGER, K.; CHAUBEY, I.; ARNOLD, J. SWATMOD-Prep: Graphical User Interface for Preparing Coupled SWAT-MODFLOW Simulations. Journal of the American Water Resources Association (JAWRA), v. 53., n. 2, p. 400-410, 2017. Disponível em: https://doi.org/10.1111/1752$\underline{1688.12502}$

BLAINSKI, E.; PORRAS, E.A.A.; GARBOSSA, L.H.P.; PINHEIRO A. Simulation of land use scenarios in the Camboriú River Basin using the SWAT model. Revista Brasileira de Recursos Hídricos - RBRH, v. 22, e. 33, $2017 . \quad$ Disponível em: https://www.scielo.br/j/rbrh/a/fd8jxjYcw8NwwxmvSsmTg $\underline{x P / ? \text { lang=en. }}$.

CAMPOS, J.E.G.; FREITAS-SILVA, F.H. Hidrogeologia do Distrito Federal. In: Inventário hidrogeológico e dos recursos hídricos superficiais do Distrito Federal. Parte I. Vol II. IEMA-SEMATEC/ Universidade de Brasília. (Inédito). 66p. 1998.

CHO, J.; BARONE, V.A.; MOSTAGHIMI, S. Simulation of land use impacts on groundwater levels and streamflow in a Virginia watershed. Agricultural Water Management, v. 96, I-II, 2009. Disponível em: https://pubag.nal.usda.gov/download/21517/PDF

DAGGUPATI, P.; PAI, N.; ALE, S.; DOUGLAS-MANKIN, K.R.; ZECKOSKI, R.W.; JEONG, J.; PARAJULI, P.B.; SARASWAT, D.; YOUSSEF, M.A. A recommended calibration and validation strategy for hydrologic and water quality models. Trans. ASABE, v. 58, n. 6, p.17051719, 2015.2 Disponível em: https://elibrary. asabe.org/abstract. asp? aid $=46545 \& \mathrm{t}=3$ \& $\underline{\text { dabs }=\text { Y } \& \text { redir }=\& \text { redirType }=}$
DE GRAAF, I.E.M.; GLEESON, T.; (RENS) VAN BEEK, L.P.H.; SUTANUDJAJA, E.H.; BIERKENS, M.F.P. Environmental flow limits to global groundwater pumping. Nature, 574, p. 90-94, 2019. Disponível em: https://www.nature.com/articles/s41586-019-1594-4

FERREIRA, R. G.; DIAS, R. L. S.; CASTRO, J. de C.; SANTOS, V. J. dos; CALIJURI, M. L.; SILVA, D. D. da. Performance of hydrological models in fluvial flow simulation. Ecological Informatics, v. 66, 101453, 2021. Disponível em: https://doi.org/10.1016/j.ecoinf.2021.101453

FERRIGO, S. Análise de consistência dos parâmetros do modelo SWAT obtidos por calibração automática - estudo de caso da Bacia do Lago Descoberto - DF. Brasília-DF: Programa de PósGraduação em Tecnologia Ambiental e Recursos Hídricos da Universidade de Brasília, 2014. 147p. Disponível

em: https://repositorio.unb.br/bitstream/10482/15629/1/2014 SaraFerrigo.pdf.

FORTES, P.T.F.O; JOFFILY, C.M.L.C.; OLIVEIRA, M.L.; BAXE, O.S.S.; ALMEIDA, W.M. Geoprocessamento aplicado ao planejamento e gestão ambiental na região do Núcleo rural Lago Oeste, Sobradinho, Distrito Federal: Resultados preliminares. XI Simpósio Brasileiro de Sensoriamento Remoto, p. 1795-1802, 2003, Belo Horizonte, Brasil. Disponível em: http://marte.sid.inpe.br/col/lid.inpe.br/sbsr/2002/11.16.1 6.16/doc/14 271.pdf

FREDERIKSEN, R. R.; MOLINA-NAVARRO, E. The importance of subsurface drainage on model performance and water balance in a agricultural catchment using SWAT and SWAT-MODFLOW. Agricultural Water Management, v. 255, 107058, $2021 . \quad$ Disponível em: https://doi.org/10.1016/j.agwat.2021.107058

FREITAS-SILVA, F.H.; CAMPOS, J.E.G. Geologia do Distrito Federal. In: Inventário Hidrogeológico e dos Recursos Hídricos Superficiais do Distrito Federal. Brasília. IEMA/SEMATEC/UnB. 1 CD-Rom. 1998.

FREITAS-SILVA, F.H; CAMPOS, J.E.G. Mapa Geológico do Distrito Federal (Eliminadas as Coberturas Recentes). Escala 1:100000. 1998.

GAO, H. Groundwater modeling for flow systems with complex geological and hydrogeological conditions. Procedia Earth and Planetary Science, v. 3, p. 23-28, 2011. Disponível em: https://www.sciencedirect.com/science/article/pii/S1878 $\underline{522011000622}$.

GASSMAN, P.W.; REYES, M.R.; GREEN, C.H.; ARNOLD, J.G. The Soil and Water Assessment Tool: Historical development, applications and future research 
directions. American Society of Agricultural and Biological Engineers - ASABE, v. 50, n. 4, p. 1211 1250, $2007 . \quad$ Disponível em: https://elibrary.asabe.org/abstract.asp?aid=23637.

GONÇALVES, T.D. (2012). Recursos hídricos no Distrito Federal: modelagem hidrológica para subsidiar a gestão sustentável na bacia do Ribeirão Pipiripau. Programa de Pós-Graduação em Geociências Aplicadas da Universidade de Brasília, 2012, 134p. Disponível em: https://repositorio.unb.br/bitstream/10482/12196/1/2012 TatianaDinizGoncalves.pdf.

GOVERNO DO DISTRITO FEDERAL - GDF. Decreto no 22018, de 20 de março de 2001. Dispõe sobre a outorga e a cobrança pelo direito de uso da água subterrânea no território do Distrito Federal... e dá outras providências. 2001 Disponível em: http://www.sinj.df.gov.br/sinj/

Greentec Tecnologia Ambiental - GREENTEC. Estudo de Impacto Ambiental - EIA: Núcleo Rural Lago Oeste. 2010.

Greentec Tecnologia Ambiental - GREENTEC. Estudo de Impacto Ambiental - EIA: (Complementações) Núcleo Rural Lago Oeste. 2014.

GUIRA, M. Numerical modeling of the effects of land use change and irrigation on streamflow depletion of Frenchman creek, Nebraska. Dissertations \& Theses in Earth and Atmospheric Sciences - University of Nebraska, 2018, 103p. Disponível em: https://digitalcommons.unl.edu/geoscidiss/103/.

GUPTA, H. V.; SOROOSHIAN, S; YAPO, P. O. Status of automatic calibration for hydrologic models: Comparison with multilevel expert calibration. Journal of Hydrologic Engineering, v. 4, n. 2, p. 135-143, 1999. Disponível em: $\quad$ https://doi.org/10.1061/(ASCE)1084$\underline{0699(1999) 4: 2(135)}$

GUZMAN, J.A.; MORIASI, D.N.; GOWDA, P.H.; STEINER, J.L.; STARKS, P.J.; ARNOLD, J.G.; SRINIVASAN, R. A model integration framework for linking SWAT and MODFLOW. Environmental Modelling \& Software, v. 73, p. 103-116, 2015. Disponível em: https://www.sciencedirect.com/science/article/pii/S1364 815215300372.

HARBAUGH, A.W. MODFLOW-2005, The U.S. Geological Survey modular ground-water model - the Ground-Water Flow Process. U.S. Geological Survey Techniques and Methods 6-A16. Virgínia, EUA, 2005. Disponível em: https://pubs.usgs.gov/tm/2005/tm6A16/.

HU, J.; MA, J.; NIE, C.; XUE, L.; ZHANG, Y.; NI, F.; DENG, Y.; LIU, J.; ZHOU, D.; LI, L.; WANG, Z. Attribution analysis of runoff change in Min-Tuo river basin based on SWAT model simulations. China, Scientific Reports, 10, n. 2900, 2020. Disponível em: https://doi.org/10.1038/s41598-020-59659-z

JEYRANI, F.; MORID, S.; SRINIVASAN, R. Assessing basin blue-green available water components under different management and climate scenarios using SWAT. Agricultural Water Management, v. 256, 107074, 2021. Disponível em: https://doi.org/10.1016/j.agwat.2021.107074

KE, K.Y. Application of an integrated surface watergroundwater model to multi-aquifers modeling in Choushui River alluvial fan, Taiwan. Hydrological Processes, v. 28, p. 1409-1421, 2014. Disponível em: https://onlinelibrary.wiley.com/doi/abs/10.1002/hyp.967 ㅇ.

KIM, N.W.; CHUNG, I.M; WON, Y.S.; ARNOLD, J.G. Development and application of the integrated SWATMODFLOW model. Journal of Hydrology, 356, p. 1-16, $2008 . \quad$ Disponível em: https://doi.org/10.1016/i.jhydrol.2008.02.024

KONDO, T.; SAKAI, N.; YAZAWA, T. SHIMIZU, Y. Verifying the applicability of SWAT to simulate fecal contamination for watershed management of Selangor Tiver, Malaysia. Science of the total Environment, v. 774, 145075, 2021. Disponível em: https://doi.org/10.1016/..scitotenv.2021.145075

KOUCHI, D.H.; ESMAILI, K.; FARIDHOSSEINI, A.; SANAEINEJAD, S.H.; KHALILI, D.; ABBASPOUR, K.C. Sensitivity of Calibrated Parameters and Water Resource Estimates on Different Objective Functions and Optimization Algorithms. Water, v. 9, n. 6, 384, 2017. Disponível em: https:/www.mdpi.com/20734441/9/6/384.

KRAUSE, P.; BOYLE, D. P.; BÄSE, F. Comparison of different efficiency criteria for hydrological model assessment. Advances in Geosciences, European Geosciences Union, v. 5, p. 89-97, 2005. Disponível em: https://adgeo.copernicus.org/articles/5/89/2005/.

LIMA, J. E. F. W.; SILVA, E. M. da; SILVA, F. A. M. da, MULLER, A. G.; SANO, E. E. Variabilidade espaçotemporal da vazão específica média no estado do Goiás. In: II Simpósio Internacional de Savanas Tropicais, 2008, Brasília, Anais... p 1-6, 2008. Disponível em: http://simposio.cpac.embrapa.br/simposio pc210/trabal hos pdf/00738 trab1 ap.pdf

LIU, W.; PARK, S.; BAILEY, R. T.; MOLINA-NAVARRO, E.; ANDERSEN, H. E.; THODSEN, H.; NIELSEN, A.; JEPPENSEN, E.; JENSEN, J. S.; JENSEN, J. B.; TROLLE, D. Comparing SWAT with SWAT-MODFLOW hydrological simulations when assessing the impacts of groundwater abstractions for irrigations and drinking 
water. Hydrology and Earth System Sciences, 2019. Disponível em: https://doi.org/10.5194/hess-2019-232

MARIANO, W. M. S. Urbanização e inundações: modelagem hidrológica de três cenários distintos de uso e ocupação do solo na Bacia do Córrego do Pinheirinho, Várzea Paulista, SP. Trabalho de Conclusão de Curso, Departamento de Geografia, Universidade de São Paulo, 109p, 2021. Disponível em: https://repositorio.usp.br/directbitstream/15a356d0-

a00b-4654-8da3-

00ad926bde67/2021 WendelMarcosSabatineMariano TGI compressed.pdf

MORIASI, D.N.; ARNOLD, J.G.; VAN LIEW, M.W.; BINGER, R.L.; HARMEL, R.D.; VEITH, T. Model evaluation guidelines for systematic quantification of accuracy in watershed simulations. Trans ASABE, v. 50, p. 885-900, 2007. Disponível em: https://doi.org/10.13031/2013.23153

NASH, J.E.; SUTCLIFFE, J.V. River flow forecasting through conceptual models. Part 1: discussion of principles. Journal of Hydrology, v. 10, p. 282-290, $1970 . \quad$ Disponível em: https://www.sciencedirect.com/science/article/pii/00221 69470902556.

NEITSCH, S. L.; ARNOLD, J. G.; KINIRY, J.R.; WILLIAMS, J.R. Soil and water assessment tool Documentação teórica versão 2009. Technical Report - 406. Centro de pesquisa de Blackland Centro de pesquisas Texas AgriLife, 634p, 2011. Disponível em: https://swat.tamu.edu/media/99193/swat2009-theoryportuguese.pdf

NETTO, P. B. (Org.) (2005). APA de Cafuringa: a última fronteira natural do DF. Brasília: SEMARH.

PERKINS, S.P.; SOPHOCLEOUS, M. Development of a comprehensive watershed model applied to study stream yield under drought conditions. Groundwater, v. 37, n. 3, p. 418-426, 1999.

Plano Diretor de Ordenamento Territorial do Distrito Federal - PDOT. Documento Técnico, 332p, 2009.

PRIYA, R. Y.; MANJULA, R. A review for comparing SWAT and SWAT coupled models and its applications. Materials Today: Proceedings, v. 45, p. 7190-7194, 2021.

REATTO, A.; MARTINS, E.S.; FARIAS, M.F.R.; SILVA, A.V.; CARVALHO, O.A., JR. Mapa Pedológico DigitalSIG Atualizado do Distrito Federal, Escala 1:100.000 e uma Síntese do Texto Explicativo (Technical Report: Digital Pedology Map-Updated GIS of the Federal District, Scale 1:100,000 and a Synthesis of Explanatory Text). Empresa Brasileira de Solos (EMBRAPA), Planaltina-DF: Brasília, Brasil, 2004, 31p. Disponível
https://ainfo.cnptia.embrapa.br/digital/bitstream/CPAC2009/26344/1/doc 120.pdf.

REITZ, K.; DIAS, S. F. Análise comparativa da aplicação de métodos de calibragem de curvas-chave de estações instáveis na análise de consistência de dados fluviométricos na estação Barreirinha, no rio AutiParaná, na bacia hidrográfica do rio Amazonas. Revista Brasileira de Recursos Hídricos - RBRH, v. 19, n. 1, p. 155-163, 2014. Disponível em: https://doi.org/10.21168/rbrh.v19n1.p155-163

RODRIGUES, E.L.; ELMIRO, M.A.T.; BRAGA, F.A.; JACOBI, C.M.; ROSSI, R.D. Impact of changes in land use in the flow of the Pará River Basin, MG. Revista Brasileira de Engenharia Agrícola e Ambiental, v.19, n.1, p.70-76, 2015. Disponível em: https://www.scielo.br/j/rbeaa/a/SFsTGrgwabXLmmvk4b cqDwt/?lang=en.

ROLIM, P. A. M.; QUEIROZ, J. C. B.; JESUS, E. S.; OLIVEIRA, L. L. Uso da modelagem hidrológica para a calibração de curva-chave de vazão em Rio Amazônico com efeito de remanso. Revisa Íbero Americana de Ciências Ambientais, v. 11, n. 5, p. 273-283, 2020. Disponível em: https://doi.org/10.6008/CBPC2179$\underline{6858.2020 .005 .0026}$

SANTOS, H. G. dos; JACOMINE, P. K. T.; ANJOS, L. H. C. dos; OlIVEIRA, V. A. de; LUMBRERAS, J. F.; COELHO, M. R.; ALMEIDA, J. A. de; ARAUJO FILHO, J. C. de; OLIVEIRA, J. B. de; CUNHA, T. J. F. Sistema Brasileiro de Classificação de Solos. Embrapa, Brasília, DF, 5a edição revisada e ampliada, 356p, 2018. Disponível em: https://www.embrapa.br/busca-depublicacoes/-/publicacao/1107206/sistema-brasileirode-classificacao-de-solos

SANTOS, R.M.; KOIDE, S. Avaliação da Recarga de Águas Subterrâneas em Ambiente de Cerrado com Base em Modelagem Numérica do Fluxo em Meio Poroso Saturado. Revista Brasileira de Recursos Hídricos RBRH vol. 21 nํ⒉ Porto Alegre abr./jun 2016 p. 451465, 2016.

SARASWAT, D.; FRANKENBERG, J.R.; PAI, N.; ALE, S.; DAGGUPATI, P.; DOUGLAS-MANKIN, K.R.; YOUSSEF, M.A. Hydrologic and water quality models: documentation and reporting procedures for calibration, validation, and use. American Society of Agricultural and Biological Engineers - ASABE, v. 58, n. 6, p. 1787-1797, 2015. Disponível em: https://elibrary.asabe.org/abstract.asp?aid=46542.

SEKERCIOGLU, C. H. Ecosystem functions and services. In: Conservation Biology for all (eds. Sodhi, N. S.; EHRLICH, P. R.), p. 45-72, 2010. Oxford University Press, Oxford. 
SERVAT, E.; DEZETTER, A. Selection of calibration objective functions in the context of rainfall-runoff modeling in a Sudanese savannah area. Hydrological Sciences Journal, v. 36, n. 4, p. 307-330, 1991. Disponível em: https://www.tandfonline.com/doi/abs/10.1080/02626669 109492517.

SILVA, F. das C. P.; GOMES, E. R. Uso e ocupação do solo e seus reflexos no escoamento superficial na microbacia hidrográfica do riacho Itacaré em Teresina PI. Revista da Academia de Ciências d Piauí, v. 2, p. 281-300, 2021. Disponível em: https://periodicos.ufpi.br/index.php/acipi/article/view/918 $\underline{1828}$

SINGH, L.; SARAVANAN, S.; JENNIFER, J. Assessing impact of land use/land cover changes on stream flow in Noyyal river catchment using ArcSWAT Model. In: International SWAT Conference, IIT Madras, Chennai, India. 2018. Disponível em: https://swat.tamu.edu/media/115979/3-leelambar-g2session.pdf.

SOPHOCLEOUS, M.; PERKINS, S.P. "Methodology and application of combined watershed and ground-water models in Kansas". Journal of Hydrology, v. 236, p. 185-201, 2000.

SOPHOCLEOUS, M.A.; KOELLIKER, J.K.; GOVINDARAJU, R.S.; BIRDIE, T.; RAMIREDDYGARI, S.R.; PERKINS, S.P. Integrated numerical modeling for basin-wide water management: The case of the Rattlesnake Creek basin in south-central Kansas. Journal of Hydrology, v. 214, p. 179-196, 1999. Disponível em:
SZYMKIEWICZ, A.; POTRYKUS, D.; JAWORSKASZULC, B.; GUMULA-KAWECKA, A.; PRUSZKOWSKA-CACERES, M.; DZIERZBICKAGLOWACKA, L. Evaluation of the influence of farming practices and land use on groundwater resources in a coastal multi-aquifer system in Puck region (northern Poland). Water, v. 12, n. 4, 1042, 2020. Disponível em: https://www.mdpi.com/2073-4441/12/4/1042.

TÁVORA, B.E. Zona Ripária de Cerrado: Processos Hidrossedimentológicos. Brasília-DF: Programa de Pós-Graduação em Tecnologia Ambiental e Recursos Hídricos da Universidade de Brasília, 2017. 130p. Disponível em: https://repositorio.unb.br/bitstream/10482/31243/1/2017 BrunoEstevesT\%c3\%a1vora.pdf.

WANG, Z.; LUO, Y.; ZHU, X.; WANG, R.; LI, W.; ZHANG, M. Watershed modelling of surface watergroundwater interaction under projected climate change and water management in the Haihe River Basin, China. British Journal of Environment \& Climate Change, v. 3, n. 3, p. 421-443, 2013. Disponível em: https://doi.org/10.9734/BJECC/2013/2673

ZAMBRANO-BIGIARINI, M. hydroGOF: goodness-offit functions for comparison of simulated and observed hydrological time series. R package Version 0.3-7. 2013. Disponível em: http://CRAN.Rproject.org/package=hydroGOF.

ZHANG, H.; WANG, B.; LIU, D. L.; ZHANG, M.; LESLIE, L. M.; YU, Q. Using improved SWAT model to simulate hydrological responses to land use change: A case study of a catchment in tropical Australia. Journal of Hydrology, v. 585, 124822, 2020. Disponível em: https://doi.org/10.1016/j.jhydrol.2020.124822 